\title{
Synthesis of Antimitotic Analogs of the Microtubule Stabilizing Sponge Alkaloid Ceratamine A
}

\author{
Matt Nodwell, Jenna L. Riffell, Michel Roberge, and Raymond J. Andersen \\ Departments of Chemistry and Earth \& Ocean Sciences, University of British Columbia, Vancouver, B.C., CANADA, V6T 1Z1 and \\ Department of Biochemistry and Molecular Biology, University of British Columbia, Vancouver, B.C., CANADA, V6T 1Z3
}

Index:

Pages SI2 to SI5: Experimental details for synthetic transformations

Page SI6: ${ }^{1} \mathrm{H}$ NMR spectrum of aldehyde 6 recorded in $\mathrm{CDCl}_{3}$ at $400 \mathrm{MHz}$.

Page SI7: ${ }^{13} \mathrm{C}$ NMR spectrum of aldehyde 6 recorded in $\mathrm{CDCl}_{3}$ at $100 \mathrm{MHz}$.

Page SI8: ${ }^{1} \mathrm{H}$ NMR spectrum of methyl ester 9 recorded in $\mathrm{CDCl}_{3}$ at $400 \mathrm{MHz}$.

Page SI9: ${ }^{13} \mathrm{C}$ NMR spectrum of methyl ester 9 recorded in $\mathrm{CDCl}_{3}$ at $100 \mathrm{MHz}$.

Page SI10: ${ }^{1} \mathrm{H}$ NMR spectrum of vinyl bromide 11 recorded in $\mathrm{CD}_{2} \mathrm{Cl}_{2}$ at $600 \mathrm{MHz}$.

Page SI11: ${ }^{13} \mathrm{C}$ NMR spectrum of vinyl bromide 11 recorded in $\mathrm{CD}_{2} \mathrm{Cl}_{2}$ at $150 \mathrm{MHz}$.

Page SI12: ${ }^{1} \mathrm{H}$ NMR spectrum of $\mathrm{HOBt}$ ester 13 recorded in $\mathrm{CD}_{2} \mathrm{Cl}_{2}$ at $400 \mathrm{MHz}$.

Page SI13: ${ }^{13} \mathrm{C}$ NMR spectrum of $\mathrm{HOBt}$ ester 13 recorded in $\mathrm{CD}_{2} \mathrm{Cl}_{2}$ at $100 \mathrm{MHz}$.

Page SI14: ${ }^{1} \mathrm{H}$ NMR spectrum of N-methylamide 14 recorded in $\mathrm{CD}_{2} \mathrm{Cl}_{2}$ at $600 \mathrm{MHz}$.

Page SI15: ${ }^{13} \mathrm{C}$ NMR spectrum of N-methylamide 14 recorded in $\mathrm{CD}_{2} \mathrm{Cl}_{2}$ at $150 \mathrm{MHz}$.

Page SI16: ${ }^{1} \mathrm{H}$ NMR spectrum of imidazoazepinone 15 recorded in $\mathrm{CD}_{2} \mathrm{Cl}_{2}$ at $600 \mathrm{MHz}$.

Page SI17: ${ }^{13} \mathrm{C}$ NMR spectrum of imidazoazepinone 15 recorded in $\mathrm{CD}_{2} \mathrm{Cl}_{2}$ at $150 \mathrm{MHz}$.

Page SI18: ${ }^{1} \mathrm{H}$ NMR spectrum of imidazoazepinone 19 recorded in $\mathrm{CD}_{2} \mathrm{Cl}_{2}$ at $600 \mathrm{MHz}$.

Page SI19: ${ }^{13} \mathrm{C}$ NMR spectrum of imidazoazepinone 19 recorded in $\mathrm{CD}_{2} \mathrm{Cl}_{2}$ at $150 \mathrm{MHz}$.

Page SI20: ${ }^{1} \mathrm{H}$ NMR spectrum of aminoimidazoazepinone 20 recorded in $\mathrm{CD}_{2} \mathrm{Cl}_{2}$ at $600 \mathrm{MHz}$.

Page SI21: ${ }^{13} \mathrm{C}$ NMR spectrum of aminoimidazoazepinone 20 recorded in $\mathrm{CD}_{2} \mathrm{Cl}_{2}$ at $150 \mathrm{MHz}$.

Page SI22: ${ }^{1} \mathrm{H}$ NMR spectrum of ceratamine 21 recorded in $\mathrm{CD}_{3} \mathrm{OD}$ at $600 \mathrm{MHz}$.

Page SI23: ${ }^{13} \mathrm{C}$ NMR spectrum of ceratamine 21 recorded in $\mathrm{CD}_{3} \mathrm{OD}$ at $150 \mathrm{MHz}$.

Page SI24: HMBC spectrum of ceratamine 21 recorded in $\mathrm{CD}_{3} \mathrm{OD}$ at $600 \mathrm{MHz}$.

Page SI25: Expanded HMBC spectrum of ceratamine 21 recorded in $\mathrm{CD}_{3} \mathrm{OD}$ at $600 \mathrm{MHz}$.

Page SI26: ${ }^{1} \mathrm{H}$ NMR spectrum of ceratamine 22 recorded in $\mathrm{CD}_{3} \mathrm{OD}$ at $600 \mathrm{MHz}$.

Page SI27: $\mathrm{HMBC}$ spectrum of ceratamine 22 recorded in $\mathrm{CD}_{3} \mathrm{OD}$ at $600 \mathrm{MHz}$.

Page SI28: Expanded HMBC spectrum of ceratamine 22 recorded in $\mathrm{CD}_{3} \mathrm{OD}$ at $600 \mathrm{MHz}$.

Page SI29: ${ }^{1} \mathrm{H}$ NMR spectrum of thiomethylimidazoazepinone 23 recorded in $\mathrm{CD}_{2} \mathrm{Cl}_{2}$ at $600 \mathrm{MHz}$.

Page SI30: ${ }^{13} \mathrm{C}$ NMR spectrum of thiomethylimidazoazepinone 23 recorded in $\mathrm{CD}_{2} \mathrm{Cl}_{2}$ at $150 \mathrm{MHz}$.

Page SI31: ${ }^{1} \mathrm{H}$ NMR spectrum of imidazoazepinone 24 recorded in $\mathrm{CD}_{2} \mathrm{Cl}_{2}$ at $600 \mathrm{MHz}$.

Page SI32: ${ }^{13} \mathrm{C}$ NMR spectrum of imidazoazepinone 24 recorded in $\mathrm{CD}_{2} \mathrm{Cl}_{2}$ at $150 \mathrm{MHz}$.

Page SI33: Antimitotic activity of ceratamine A (1) and analog 21. 
General Methods. All non-aqueous reactions were carried out in flame-dried glassware unless otherwise noted. Air and moisture sensitive liquid reagents were manipulated via a dry syringe. Anhydrous tetrahydrofuran (THF) was obtained from distillation over sodium. All other solvents and reagents were used as obtained from commercial sources without further purification. ${ }^{1} \mathrm{H}$ and ${ }^{13} \mathrm{C}$ spectra were obtained on Bruker Avance 400 direct or Bruker Avance 600 cryoprobe spectrometers. Flash chromatography was performed using Silicycle Ultra Pure silica gel (230-400 mesh).

\section{1-Benzyloxymethyl-2-methylsulfanyl-5-tributylstannanyl-1H-imidazole-4-carbaldehyde (6). BOM} protected tribromoimidazole $3(6.82 \mathrm{~g}, 16.05 \mathrm{mmol})$ was dissolved under Ar in $80 \mathrm{~mL}$ dry THF, and the solution was cooled to $-78^{\circ} \mathrm{C}$. nBuLi $(10.0 \mathrm{~mL}, 1.6 \mathrm{M}, 16.05 \mathrm{mmol})$ was added over a period of $7 \mathrm{~min}$, and the solution was stirred for $20 \mathrm{~min}$. MeSSMe $(1.42 \mathrm{~mL}, 16.05 \mathrm{mmol})$ was then quickly added, and the solution was stirred cold for 6 min. The cold bath was removed and replaced with a water bath, and the reaction was stirred for 10 min. The reaction was re-cooled to $-78^{\circ} \mathrm{C}$ and $\mathrm{nBuLi}(10.0 \mathrm{~mL})$ was slowly added. After $30 \mathrm{~min}, \mathrm{Bu} 3 \mathrm{SnCl}$ $(4.33 \mathrm{~mL}, 16.05 \mathrm{mmol})$ was added, and the solution was stirred cold for $5 \mathrm{~min}$. The cryobath was replaced with a waterbath, and the reaction was stirred for an additional $15 \mathrm{~min}$. The reaction was cooled to $-78^{\circ} \mathrm{C}$, and $\mathrm{nBuLi}$ $(10.0 \mathrm{~mL})$ was slowly added. The reaction was stirred cold for $30 \mathrm{~min}$, then DMF $(3 \mathrm{~mL})$ was very slowly added. The reaction was stirred for $1 \mathrm{~h}$ at $-78^{\circ} \mathrm{C}$, and then allowed to slowly warm to RT. After $10 \mathrm{~min}$ at RT, the reaction was quenched with the addition of $\mathrm{H}_{2} \mathrm{O}$. The crude reaction was extracted into EtOAc, and washed with $3 \times \mathrm{H}_{2} \mathrm{O}$. The organic phase was dried over $\mathrm{Na}_{2} \mathrm{SO}_{4}$, filtered and concentrated. The crude product was purified by column chromatography to yield $6\left(4.2 \mathrm{~g}, 7.6 \mathrm{mmol}, 48 \%\right.$ yield) as a pale yellow oil. ${ }^{1} \mathrm{H}$ NMR (400 $\left.\mathrm{MHz} \mathrm{CDCl}_{3}\right) \delta 0.85(\mathrm{t}, 7.2 \mathrm{~Hz}, 9 \mathrm{H}), 1.16(\mathrm{~m}, 6 \mathrm{H}), 1.28(\mathrm{~m}, 6 \mathrm{H}), 1.46(\mathrm{~m}, 6 \mathrm{H}), 2.71(\mathrm{~s}, 3 \mathrm{H}), 4.48(\mathrm{~s}, 2 \mathrm{H}), 5.34$ (s, 2H), $7.31(\mathrm{~m}, 5 \mathrm{H}), 9.84(\mathrm{~s}, 1 \mathrm{H}) ;{ }^{13} \mathrm{C} \mathrm{NMR}\left(100 \mathrm{MHz}, \mathrm{CDCl}_{3}\right) \delta$ 12.3, 14.6, 17.0, 28.2, 29.9, 71.5, 76.5, $128.5,129.0,129.4,137.5,145.4,151.2,151.9,187.7$

HRESIMS calcd for $\mathrm{C}_{25} \mathrm{H}_{40} \mathrm{~N}_{2} \mathrm{O}_{2} \mathrm{SSnNa} 575.1730$, found 575.1740

\section{2-(3-Benzyloxymethyl-5-formyl-2-methylsulfanyl-3H-imidazol-4-yl)-3-(4-methoxy-phenyl)-acrylic acid} methyl ester (9). Stannane 6 (3.8g, 6.89mmol), bromide 8 (2.15g, 7.58mmol), $\mathrm{Pd}\left(\mathrm{PPh}_{3}\right)_{4}(875 \mathrm{mg}, 0.76 \mathrm{mmol})$ and $\mathrm{CuI}(1.31 \mathrm{~g}, 6.89 \mathrm{mmol})$ were combined under Ar. Dry toluene $(60 \mathrm{~mL})$ was added, and the solution was refluxed for $2.5 \mathrm{~h}$. The solution was cooled and concentrated to dryness. The residue was redissolved in $\mathrm{CH}_{2} \mathrm{Cl}_{2}$, filtered through celite and concentrated. The crude product was purified by column chromatography to yield $9\left(2.77 \mathrm{~g}, 6.12 \mathrm{mmol}, 90 \%\right.$ yield) as a pale yellow solid. ${ }^{1} \mathrm{H} \mathrm{NMR}\left(400 \mathrm{MHz}, \mathrm{CDCl}_{3}\right) \delta 2.79(\mathrm{~s}, 3 \mathrm{H}), 3.71$ $(\mathrm{s}, 3 \mathrm{H}), 3.76(\mathrm{~s}, 3 \mathrm{H}), 4.37(\mathrm{~s}, 2 \mathrm{H}), 5.00(\mathrm{~d}, 10.9 \mathrm{~Hz}, 1 \mathrm{H}), 5.08(\mathrm{~d}, 10.9 \mathrm{~Hz}, 1 \mathrm{H}), 6.76(\mathrm{~d}, 8.7 \mathrm{~Hz}, 2 \mathrm{H}), 7.02(\mathrm{~d}$, $8.7 \mathrm{~Hz}, 2 \mathrm{H}), 7.12(\mathrm{~m}, 2 \mathrm{H}), 7.27(\mathrm{~m}, 3 \mathrm{H}), 8.10(\mathrm{~s}, 1 \mathrm{H}), 9.73(\mathrm{~s}, 1 \mathrm{H}) ;{ }^{13} \mathrm{C} \mathrm{NMR}\left(100 \mathrm{MHz}, \mathrm{CDCl}_{3}\right) \delta 16.4,53.6$, $56.4,71.8,74.2,115.6,126.5,128.5,129.0,129.4,133.4,135.3,137.2,137.7,139.9,148.1,149.6,162.8$, $167.3,184.9$

HRESIMS calcd for $\mathrm{C}_{24} \mathrm{H}_{24} \mathrm{~N}_{2} \mathrm{O}_{5} \mathrm{SNa} 475.1304$, found 475.1307

\section{2-[3-Benzyloxymethyl-5-(2-bromo-vinyl)-2-methylsulfanyl-3H-imidazol-4-yl]-3-(4-methoxy-phenyl)-} acrylic acid methyl ester (11). (Bromomethyl)triphenylphosphonium bromide (502mg, 1.15mmol) was suspended under Ar in 10mL dry THF. LiHMDS (1.06mL, 1.0M in THF, 1.06mmol) was added and the resulting bright yellow solution was stirred at RT for $30 \mathrm{~min}$. The solution was cooled to $-78^{\circ} \mathrm{C}$ and $1.2 \mathrm{~mL}$ HMPA was added. After $5 \mathrm{~min}$, a solution of ester $9(372 \mathrm{mg}, 0.822 \mathrm{mmol})$ in $3 \mathrm{~mL}$ dry THF was added over a period of $5 \mathrm{~min}$. The reaction was stirred for $2 \mathrm{~h}$ at $-78^{\circ} \mathrm{C}$, after which satd. $\mathrm{NaHCO}_{3}$ was added to the cold reaction. The reaction was allowed to warm to $\mathrm{RT}$, and the crude product was extracted with EtOAc. The organic phase was washed with $2 \mathrm{x} \mathrm{H}_{2} \mathrm{O}$, dried over $\mathrm{Na}_{2} \mathrm{SO}_{4}$, filtered and concentrated. The crude compound was purified by column chromatography to yield bromide $\mathbf{1 1}(312 \mathrm{mg}, 0.59 \mathrm{mmol}, 71 \%$ yield) as a bright yellow 
solid. ${ }^{1} \mathrm{H}$ NMR (600 MHz, $\left.\mathrm{CD}_{2} \mathrm{Cl}_{2}\right) \delta 2.75(\mathrm{~s}, 3 \mathrm{H}), 3.68(\mathrm{~s}, 3 \mathrm{H}), 3.77(\mathrm{~s}, 3 \mathrm{H}), 4.37(\mathrm{~s}, 2 \mathrm{H}), 5.08(\mathrm{~d}, 11.1 \mathrm{~Hz}$, $1 \mathrm{H}), 5.12(\mathrm{~d}, 11.1 \mathrm{~Hz}, 1 \mathrm{H}), 6.16(\mathrm{~d}, 8.3 \mathrm{~Hz}, 1 \mathrm{H}), 6.66(\mathrm{~d}, 8.3 \mathrm{~Hz}, 1 \mathrm{H}), 7.12(\mathrm{~m}, 4 \mathrm{H}), 7.25(\mathrm{~m}, 3 \mathrm{H}), 8.03(\mathrm{~s}, 1 \mathrm{H})$; ${ }^{13} \mathrm{C}$ NMR $\left(150 \mathrm{MHz}, \mathrm{CD}_{2} \mathrm{Cl}_{2}\right) \delta 16.4,52.9,55.9,70.9,74.0,104.7,114.8,116.2,123.5,126.6,128.0,128.3$, $128.8,129.3,133.0,136.5,137.4,146.2,147.0,162.2,167.5$

HRESIMS calcd for $\mathrm{C}_{25} \mathrm{H}_{26} \mathrm{~N}_{2} \mathrm{O}_{4} \mathrm{~S}^{79} \mathrm{Br}[\mathrm{M}+\mathrm{H}]^{+}$529.0797, found 529.0782

2-[3-Benzyloxymethyl-5-(2-bromo-vinyl)-2-methylsulfanyl-3H-imidazol-4-yl]-3-(4-methoxy-phenyl)acrylic acid benzotriazol-1-yl ester (13). Bromide $11(312 \mathrm{mg}, 0.59 \mathrm{mmol})$ was dissolved in $2 \mathrm{~mL}$ THF. LiOH$\mathrm{H}_{2} \mathrm{O}(75 \mathrm{mg}, 1.78 \mathrm{mmol})$ was added, followed by $0.5 \mathrm{~mL} \mathrm{H}_{2} \mathrm{O}$. The solution was stirred rapidly for $24 \mathrm{~h}$ at RT. The reaction was then acidified, extracted into EtOAc, and the organic phase was washed with $3 \times \mathrm{H}_{2} \mathrm{O}$, dried over $\mathrm{Na}_{2} \mathrm{SO}_{4}$, filtered and concentrated. The residue was then redissolved in $2 \mathrm{~mL} \mathrm{CH}_{2} \mathrm{Cl}_{2}$, and $\mathrm{HOBt}(118 \mathrm{mg}$, $0.88 \mathrm{mmol})$ and DMAP $(\sim 1 \mathrm{mg})$ were added. The solution was stirred for $10 \mathrm{~min}$, and then DIPC (136uL, $0.88 \mathrm{mmol}$ ) was added. The reaction was stirred rapidly at RT for $1 \mathrm{~h}$, concentrated and loaded directly onto a silica column. The HOBt ester 13 was isolated as a bright yellow solid (322mg, $0.51 \mathrm{mmol}, 86 \%$ yield). ${ }^{1} \mathrm{H}$ NMR (400 MHz, $\left.\mathrm{CD}_{2} \mathrm{Cl}_{2}\right) \delta 2.80(\mathrm{~s}, 3 \mathrm{H}), 3.84(\mathrm{~s}, 3 \mathrm{H}), 4.50(\mathrm{~d}, 11.8 \mathrm{~Hz}, 1 \mathrm{H}), 4.56(\mathrm{~d}, 11.8 \mathrm{~Hz}, 1 \mathrm{H}), 5.20(\mathrm{~d}$, $10.9 \mathrm{~Hz}, 1 \mathrm{H}), 5.34(\mathrm{~d}, 10.9 \mathrm{~Hz}, 1 \mathrm{H}), 6.40(\mathrm{~d}, 8.3 \mathrm{~Hz}, 1 \mathrm{H}), 6.88(\mathrm{~d}, 8.9 \mathrm{~Hz}, 2 \mathrm{H}), 6.95(\mathrm{~d}, 8.3 \mathrm{~Hz}, 1 \mathrm{H}), 7.21(\mathrm{~m}, 2 \mathrm{H})$, $7.28(\mathrm{~m}, 6 \mathrm{H}), 7.45(\mathrm{~m}, 2 \mathrm{H}), 8.06(\mathrm{~d}, 7.4 \mathrm{~Hz}, 1 \mathrm{H}), 8.36(\mathrm{~s}, 1 \mathrm{H}) ;{ }^{13} \mathrm{C} \mathrm{NMR}\left(100 \mathrm{MHz}, \mathrm{CD}_{2} \mathrm{Cl}_{2}\right) \delta$ 16.7, 56.5, 71.8, 74.5, 107.0, 109.4, 111.1, 115.8, 121.2, 124.0, 125.7, 126.4, 126.7, 128.7, 128.9, 129.3, 129.6, 129.7, 134.7, $137.6,138.2,144.4,147.8,152.5,164.1,164.4$

HRESIMS calcd for $\mathrm{C}_{30} \mathrm{H}_{27} \mathrm{~N}_{5} \mathrm{O}_{4} \mathrm{~S}^{79} \mathrm{Br}[\mathrm{M}+\mathrm{H}]^{+}$632.0967, found 632.0978

2-[3-Benzyloxymethyl-5-(2-bromo-vinyl)-2-methylsulfanyl-3H-imidazol-4-yl]-3-(4-methoxy-phenyl)-Nmethyl-acrylamide (14). HOBt ester $13(240 \mathrm{mg}, 0.37 \mathrm{mmol})$ was dissolved in $1 \mathrm{~mL} \mathrm{DCM}$. $\mathrm{MeNH}_{2}(2.0 \mathrm{M}$ in $\mathrm{THF}$ ) was added (approx $3 \mathrm{~mL}$ ) until the bright yellow color disappeared. The solution was stirred for $1 \mathrm{~min}$, and then extracted into EtOAc. The organic phase was washed with $2 \times 0.5 \mathrm{M} \mathrm{HCl}, 1 \times \mathrm{H}_{2} \mathrm{O}, 1 \times$ satd $\mathrm{NaHCO}_{3}$. The organic phase was dried over $\mathrm{Na}_{2} \mathrm{SO}_{4}$, filtered and concentrated to yield 14 (175mg, $0.33 \mathrm{mmol}, 90 \%$ yield) as a slightly yellow foam. ${ }^{1} \mathrm{H}$ NMR $\left(600 \mathrm{MHz}, \mathrm{CD}_{2} \mathrm{Cl}_{2}\right) \delta 2.71(\mathrm{~d}, 4.7 \mathrm{~Hz}, 1 \mathrm{H}), 2.78(\mathrm{~s}, 3 \mathrm{H}), 3.76(\mathrm{~s}, 3 \mathrm{H}), 4.40$ $(\mathrm{s}, 2 \mathrm{H}), 4.93(\mathrm{~d}, 10.8 \mathrm{~Hz}, 1 \mathrm{H}), 5.07(\mathrm{~d}, 10.8 \mathrm{~Hz}, 1 \mathrm{H}), 5.71(\mathrm{~s}, \mathrm{br}, 1 \mathrm{H}), 6.27(\mathrm{~d}, 8.0 \mathrm{~Hz}, 1 \mathrm{H}), 6.74(\mathrm{~d}, 8.0 \mathrm{~Hz}, 1 \mathrm{H})$, $6.78(\mathrm{~d}, 8.9 \mathrm{~Hz}, 2 \mathrm{H}), 7.02(\mathrm{~d}, 8.9 \mathrm{~Hz}, 2 \mathrm{H}), 7.15(\mathrm{~m}, 2 \mathrm{H}), 7.29(\mathrm{~m}, 3 \mathrm{H}), 8.02(\mathrm{~s}, 1 \mathrm{H}) ;{ }^{13} \mathrm{C} \mathrm{NMR}(150 \mathrm{MHz}$, $\left.\mathrm{CD}_{2} \mathrm{Cl}_{2}\right) \delta 15.2,26.2,54.8,70.4,72.7,104.8,113.8,117.6,121.8,126.0,127.0,127.4,127.8,128.1,131.4$, $136.1,136.2,142.2,146.6,160.6,165.3$

HRESIMS calcd for $\mathrm{C}_{25} \mathrm{H}_{26} \mathrm{~N}_{3} \mathrm{O}_{3} \mathrm{~S}^{79} \mathrm{BrNa} 550.0776$, found 550.0757

3-Benzyloxymethyl-4-(4-methoxy-benzylidene)-6-methyl-2-methylsulfanyl-4,6-dihydro-3H-imidazo[4,5d]azepin-5-one (15). Amide 14 (47.7mg, 0.091 mmol), $\mathrm{CuI}(17.3 \mathrm{mg}, 0.091 \mathrm{mmol})$ and $\mathrm{Cs}_{2} \mathrm{CO}_{3}(59.2 \mathrm{mg}$, $0.18 \mathrm{mmol})$ were combined under Ar in $3 \mathrm{~mL}$ dry THF. N,N'-Dimethylethylenediamine $(20 \mu \mathrm{L}, 0.18 \mathrm{mmol})$ was added, and the solution was stirred at RT for $24 \mathrm{~h}$. The reaction was diluted with EtOAc and filtered through celite. The crude product was purified by column chromatography to yield $\mathbf{1 5}(37.6 \mathrm{mg}, 92 \%$ yield) as a bright yellow solid. ${ }^{1} \mathrm{H}$ NMR $\left(600 \mathrm{MHz}, \mathrm{CD}_{2} \mathrm{Cl}_{2}\right) \delta 2.65(\mathrm{~s}, 3 \mathrm{H}), 3.26(\mathrm{~s}, 3 \mathrm{H}), 3.76(\mathrm{~s}, 3 \mathrm{H}), 4.28(\mathrm{~d}, 11.9 \mathrm{~Hz}, 1 \mathrm{H}), 4.31$ $(\mathrm{d}, 11.9 \mathrm{~Hz}, 1 \mathrm{H}), 4.55(\mathrm{~d}, 11.3 \mathrm{~Hz}, 1 \mathrm{H}), 4.83(\mathrm{~d}, 11.3 \mathrm{~Hz}, 1 \mathrm{H}), 6.10(\mathrm{~d}, 9.1 \mathrm{~Hz}, 1 \mathrm{H}), 6.22(\mathrm{~s}, 9.1 \mathrm{~Hz}, 1 \mathrm{H}), 6.76(\mathrm{~d}$, $8.8 \mathrm{~Hz}, 2 \mathrm{H}), 6.91(\mathrm{~d}, 8.8 \mathrm{~Hz}, 2 \mathrm{H}), 7.21-7.31(\mathrm{~m}, 5 \mathrm{H}) ;{ }^{13} \mathrm{C} \mathrm{NMR}\left(150 \mathrm{MHz}, \mathrm{CD}_{2} \mathrm{Cl}_{2}\right) \delta$ 15.2, 37.5, 54.8, 70.0, 72.4, 107.6, 113.6, 121.3, 123.3, 126.6, 127.3, 127.4, 127.7, 127.8, 129.9, 133.1, 136.5, 136.6, 148.2, 159.7, 168.9

HRESIMS calcd for $\mathrm{C}_{25} \mathrm{H}_{25} \mathrm{~N}_{3} \mathrm{O}_{3} \mathrm{SNa} 470.1514$, found 470.1495

4-(4-Methoxy-benzylidene)-6-methyl-2-methylsulfanyl-4,6-dihydro-3H-imidazo[4,5-d]azepin-5-one (23) 
Compound 15 (10mg, 0.022mmol) was dissolved in $1 \mathrm{~mL} \mathrm{CH} \mathrm{Cl}_{2}$. Anhydrous $\mathrm{AlCl}_{3}(5 \mathrm{mg}, 0.038 \mathrm{mmol})$ was added and the blood red slurry was stirred at RT for $10 \mathrm{~min}$. The reaction was then cooled to $0^{\circ} \mathrm{C}$ and water was added until all solids had dissolved. EtOAc $(5 \mathrm{~mL})$ was added, and the biphasic solution was stirred rapidly for 30 min. Satd. $\mathrm{NaHCO}_{3}$ was added to the solution and the mixture was partitioned. The organic phase was dried over $\mathrm{Na}_{2} \mathrm{SO}_{4}$, filtered and concentrated. The crude product was purified by column chromatography to yield $\mathbf{2 3}$ (5mg, $0.015 \mathrm{mmol}, 68 \%$ yield) as a bright yellow solid. ${ }^{1} \mathrm{H}$ NMR $\left(600 \mathrm{MHz}, \mathrm{CD}_{2} \mathrm{Cl}_{2}\right) \delta 2.60(\mathrm{~s}, 3 \mathrm{H}), 3.12(\mathrm{~s}$, $3 \mathrm{H}), 3.78(\mathrm{~s}, 3 \mathrm{H}), 6.05(\mathrm{~d}, 9.1 \mathrm{~Hz}, 1 \mathrm{H}), 6.23(\mathrm{~d}, \mathrm{br}, 9.1 \mathrm{~Hz}, 1 \mathrm{H}), 6.74(\mathrm{~d}, 8.8 \mathrm{~Hz}, 2 \mathrm{H}), 6.88(\mathrm{~s}$, br, $2 \mathrm{H}), 7.10(\mathrm{~s}$, $1 \mathrm{H}) ;{ }^{13} \mathrm{C}$ NMR $\left(150 \mathrm{MHz}, \mathrm{CD}_{2} \mathrm{Cl}_{2}\right) \delta$ 16.4, 39.5, 55.8, 104.4, 114.0, 114.2, 127.3, 128.6, 131.2, 132.1, 143.2, $145.9,160.6,169.6$,

HRESIMS calcd for $\mathrm{C}_{17} \mathrm{H}_{18} \mathrm{~N}_{3} \mathrm{O}_{2} \mathrm{NS}[\mathrm{M}+\mathrm{H}] 328.1120$, found 335.1110

\section{3-Benzyloxymethyl-4-(4-methoxy-benzylidene)-6-methyl-4,6-dihydro-3H-imidazo[4,5-d] azepin-5-one} (19). Sulfide 15 (400mg, $0.89 \mathrm{mmol})$ was dissolved in $10 \mathrm{~mL}$ toluene. Raney nickel was added as a slurry in toluene with sonication until TLC analysis showed complete consumption of the starting material. The solution was filtered and washed with $100 \mathrm{~mL} \mathrm{MeOH}, 100 \mathrm{~mL}$ acetone and $100 \mathrm{~mL}$ EtOAc. The combined organic solutions were rotovaped to dryness. The crude product was purified by column chromatography to yield 19 (113.1mg, 0.28mmol, 31\% yield) as a light yellow solid. ${ }^{1} \mathrm{H}$ NMR (600 MHz, $\left.\mathrm{CD}_{2} \mathrm{Cl}_{2}\right) \delta 3.26(\mathrm{~s}, 3 \mathrm{H}), 3.76(\mathrm{~s}$, $3 \mathrm{H}), 4.26(\mathrm{~d}, 11.9 \mathrm{~Hz}, 1 \mathrm{H}), 4.30(\mathrm{~d}, 11.9 \mathrm{~Hz}, 1 \mathrm{H}), 4.62(\mathrm{~d}, 11.1 \mathrm{~Hz}, 1 \mathrm{H}), 4.70(\mathrm{~d}, 11.1 \mathrm{~Hz}, 1 \mathrm{H}), 6.13(\mathrm{~d}, 9.0 \mathrm{~Hz}$, $1 \mathrm{H}), 6.27(\mathrm{~d}, 9.0 \mathrm{~Hz}, 1 \mathrm{H}), 6.75(\mathrm{~d}, 8.8 \mathrm{~Hz}, 2 \mathrm{H}), 6.88(\mathrm{~d}, 8.8 \mathrm{~Hz}, 2 \mathrm{H}), 7.18(\mathrm{~s}, 1 \mathrm{H}), 7.19(\mathrm{~s}, 1 \mathrm{H}), 7.28(\mathrm{~m}, 4 \mathrm{H}), 7.76$ $(\mathrm{s}, 1 \mathrm{H}) ;{ }^{13} \mathrm{C}$ NMR $\left(150 \mathrm{MHz}, \mathrm{CD}_{2} \mathrm{Cl}_{2}\right) \delta 38.6,55.8,71.2,74.9,108.6,114.4,114.7,115.1,127.6,128.3,128.4$, $128.5,128.9,129.2,130.9,134.9,137.2,140.8,160.7,170.0$

HRESIMS calcd for $\mathrm{C}_{24} \mathrm{H}_{23} \mathrm{~N}_{3} \mathrm{O}_{3} \mathrm{Na} 424.1637$, found 424.1647

4-(4-Methoxy-benzylidene)-6-methyl-4,6-dihydro-3H-imidazo[4,5-d]azepin-5-one (24). Compound 19 (10mg, $0.025 \mathrm{mmol}$ ) was dissolved in $\mathrm{CH}_{2} \mathrm{Cl}_{2}$. $\mathrm{AlCl}_{3}(20 \mathrm{mg}, 0.15 \mathrm{mmol}$ ) was added and the deep red slurry was stirred at RT for 15 min. The reaction was quenched with the addition of $\mathrm{H}_{2} \mathrm{O}$. Satd. $\mathrm{NaHCO}_{3}$ was added and the crude compound was extracted with EtOAc. The organic phase was dried over $\mathrm{Na}_{2} \mathrm{SO}_{4}$, filtered and concentrated. The crude product was purified by column chromatography to yield $\mathbf{2 4}(5 \mathrm{mg}, 0.017 \mathrm{mmol}, 71 \%$ yield) as a yellow solid. ${ }^{1} \mathrm{H}$ NMR $\left(600 \mathrm{MHz}, \mathrm{CD}_{2} \mathrm{Cl}_{2}\right) \delta 3.06(\mathrm{~s}, 3 \mathrm{H}), 3.75(\mathrm{~s}, 3 \mathrm{H}), 6.03(\mathrm{~d}, 9.1 \mathrm{~Hz}, 1 \mathrm{H}), 6.27(\mathrm{~d}$, $9.1 \mathrm{~Hz}, 1 \mathrm{H}), 6.69(\mathrm{~d}, 8.8 \mathrm{~Hz}, 2 \mathrm{H}), 6.72(\mathrm{~d}, 8.8 \mathrm{~Hz}, 2 \mathrm{H}), 7.05(\mathrm{~s}, 1 \mathrm{H}), 7.68(\mathrm{~s}, 1 \mathrm{H}) ;{ }^{13} \mathrm{C} \mathrm{NMR}\left(150 \mathrm{MHz} \mathrm{CD}_{2} \mathrm{Cl}_{2}\right) \delta$ 39.3, 55.8, 109.2, 114.1, 122.4, 127.4, 127.9, 128.3, 130.8, 131.1, 134.3, 137.9, 160.4, 170.3

HREIMS calcd for $\mathrm{C}_{16} \mathrm{H}_{15} \mathrm{~N}_{3} \mathrm{O}_{2} 281.11643$, found 281.11651

\section{2-Amino-3-benzyloxymethyl-4-(4-methoxy-benzylidene)-6-methyl-4,6-dihydro-3H-imidazo[4,5-d]azepin- 5-one (20)}

Compound (19) $(11.7 \mathrm{mg}, 0.029 \mathrm{mmol})$ was dissolved in $2 \mathrm{~mL}$ dry THF under Ar and cooled to $-78^{\circ} \mathrm{C}$. $\mathrm{MeLi}$ (50uL, 1.6M, 0.080 mmol) was added and the resulting bright yellow solution was stirred for $10 \mathrm{~min}$ at $-78^{\circ} \mathrm{C}$. A solution of $\mathrm{TsN}_{3}(70 \mathrm{mg}, 0.35 \mathrm{mmol})$ in $2 \mathrm{~mL}$ dry THF was added slowly, and the resulting yellow solution was stirred for $10 \mathrm{~min}$ at $-78^{\circ} \mathrm{C}$. $\mathrm{H}_{2} \mathrm{O}$ was added, and the solution was allowed to warm to RT. The reaction was partitioned between EtOAc and satd $\mathrm{NaHCO}_{3}$ and the organic phase was dried over $\mathrm{Na}_{2} \mathrm{SO}_{4}$, filtered and concentrated. The crude residue was then redissolved in $\mathrm{MeOH}$, and $10 \% \mathrm{Pd} / \mathrm{C}(20 \mathrm{mg})$ was added. The solution was saturated with $\mathrm{H}_{2}$ and stirred for $30 \mathrm{~min}$ at RT. The reaction was filtered through a $0.4 \mathrm{uM} \mathrm{Millex}$ 
membrane, washed with $\mathrm{MeOH}$ and concentrated. The crude product was purified by column chromatography to yield 20 (9mg, $0.021 \mathrm{mmol}, 72 \%$ yield) as a bright yellow solid. ${ }^{1} \mathrm{H} \mathrm{NMR}\left(600 \mathrm{MHz}, \mathrm{CD}_{2} \mathrm{Cl}_{2}\right) \delta 3.26(\mathrm{~s}, 3 \mathrm{H})$, $3.76(\mathrm{~s}, 3 \mathrm{H}), 4.19(\mathrm{~d}, 11.5 \mathrm{~Hz}, 1 \mathrm{H}), 4.23(\mathrm{~d}, 11.5 \mathrm{~Hz}, 1 \mathrm{H}), 4.45(\mathrm{~s}, \mathrm{br}, 2 \mathrm{H}), 4.52(\mathrm{~s}, 2 \mathrm{H}), 6.03(\mathrm{~d}, 8.9 \mathrm{~Hz}, 1 \mathrm{H}), 6.07$ $(\mathrm{d}, 8.9 \mathrm{~Hz}, 1 \mathrm{H}), 6.77(\mathrm{~d}, 8.9 \mathrm{~Hz}, 2 \mathrm{H}), 6.97(\mathrm{~d}, 8.9 \mathrm{~Hz}, 2 \mathrm{H}), 7.18(\mathrm{~m}, 3 \mathrm{H}), 7.28(\mathrm{~m}, 3 \mathrm{H}) ;{ }^{13} \mathrm{C} \mathrm{NMR}(150 \mathrm{MHz}$, $\left.\mathrm{CD}_{2} \mathrm{Cl}_{2}\right) \delta 38.7,55.8,70.8,72.6,109.1,114.6,119.2,122.5,127.8,128.1,128.5,128.7,128.9,130.9,131.9$, $134.0,137.2,152.3,160.3,170.0$

HRESIMS calcd for $\mathrm{C}_{24} \mathrm{H}_{24} \mathrm{~N}_{4} \mathrm{O}_{3} \mathrm{Na} 439.1746$, found 439.1735

\section{2-Amino-4-[hydroxy-(4-methoxy-phenyl)-methyl]-6-methyl-6H-imidazo[4,5-d]azepin-5-one (21)}

Compound 20 (9mg, $0.021 \mathrm{mmol})$ was dissolved in $\mathrm{CH}_{2} \mathrm{Cl}_{2}(1 \mathrm{~mL})$. Anhydrous $\mathrm{AlCl}_{3}(10 \mathrm{mg}, 0.075 \mathrm{mmol})$ was added and the resulting blood red slurry was stirred at RT for $10 \mathrm{~min}$. The solution was cooled to $0^{\circ} \mathrm{C}$ and water was slowly added until all solids had dissolved. The resulting colorless biphasic system was then stirred rapidly with mixing for $30 \mathrm{~min}$, after which a bright yellow color results. Satd $\mathrm{NaHCO}_{3}$ was added, and the reaction was extracted into EtOAc. The aqueous phase was extracted a second time with EtOAc. The combined organic phases were dried over $\mathrm{Na}_{2} \mathrm{SO}_{4}$, filtered and concentrated. The crude product was purified by column chromatography to yield 21 (4mg, $0.013 \mathrm{mmol}, 62 \%$ yield) as a bright yellow solid. ${ }^{1} \mathrm{H} \mathrm{NMR}(600 \mathrm{MHz}$, $\left.\mathrm{CD}_{3} \mathrm{OD}\right) \delta 3.65(\mathrm{~s}, 3 \mathrm{H}), 3.74(\mathrm{~s}, 3 \mathrm{H}), 6.34(\mathrm{~s}, 1 \mathrm{H}), 6.59(\mathrm{~d}, 10.0 \mathrm{~Hz}, 1 \mathrm{H}), 6.80(\mathrm{~d}, 8.8 \mathrm{~Hz}, 2 \mathrm{H}), 7.42(\mathrm{~d}, 8.8 \mathrm{~Hz}$, 2H), $7.81(\mathrm{~d}, 10.0 \mathrm{~Hz}, 1 \mathrm{H}) ;{ }^{13} \mathrm{C} \mathrm{NMR}\left(150 \mathrm{MHz}, \mathrm{CD}_{3} \mathrm{OD}\right) \delta$ 45.1, 55.7, 75.3, 102.3, 114.6, 127.0, 129.2, 137.1, $145.6,160.4,160.5,165.7,173.2,176.4$

HRESIMS calcd for $\mathrm{C}_{16} \mathrm{H}_{16} \mathrm{~N}_{4} \mathrm{O}_{3} \mathrm{Na} 335.1120$, found 335.1115

\section{2-Amino-4-(4-methoxy-benzoyl)-6-methyl-6H-imidazo[4,5-d]azepin-5-one (22)}

Ketone 22 (1mg, 0.0032mmol, 15\% yield) was also isolated from the crude as a yellow solid. ${ }^{1} \mathrm{H}$ NMR (600 $\left.\mathrm{MHz}, \mathrm{CD}_{3} \mathrm{OD}\right) \delta 3.66(\mathrm{~s}, 3 \mathrm{H}), 3.86(\mathrm{~s}, 3 \mathrm{H}), 6.65(\mathrm{~d}, 10.2 \mathrm{~Hz}, 1 \mathrm{H}), 6.98(\mathrm{~d}, 8.8 \mathrm{~Hz}, 2 \mathrm{H}), 7.85(\mathrm{~d}, 8.8 \mathrm{~Hz}, 2 \mathrm{H}), 7.89$ $(\mathrm{d}, 10.2 \mathrm{~Hz}, 1 \mathrm{H}) ;{ }^{13} \mathrm{C} \mathrm{NMR}\left(150 \mathrm{MHz}, \mathrm{CD}_{3} \mathrm{OD}\right) \delta 44.3,56.2,102.4,115.1,129.9,133.3,146.2,159.5,164.6$, $165.8,173.5,193.6$

HRESIMS calcd for $\mathrm{C}_{16} \mathrm{H}_{14} \mathrm{~N}_{4} \mathrm{O}_{3} \mathrm{Na} 333.0964$, found 333.0953 

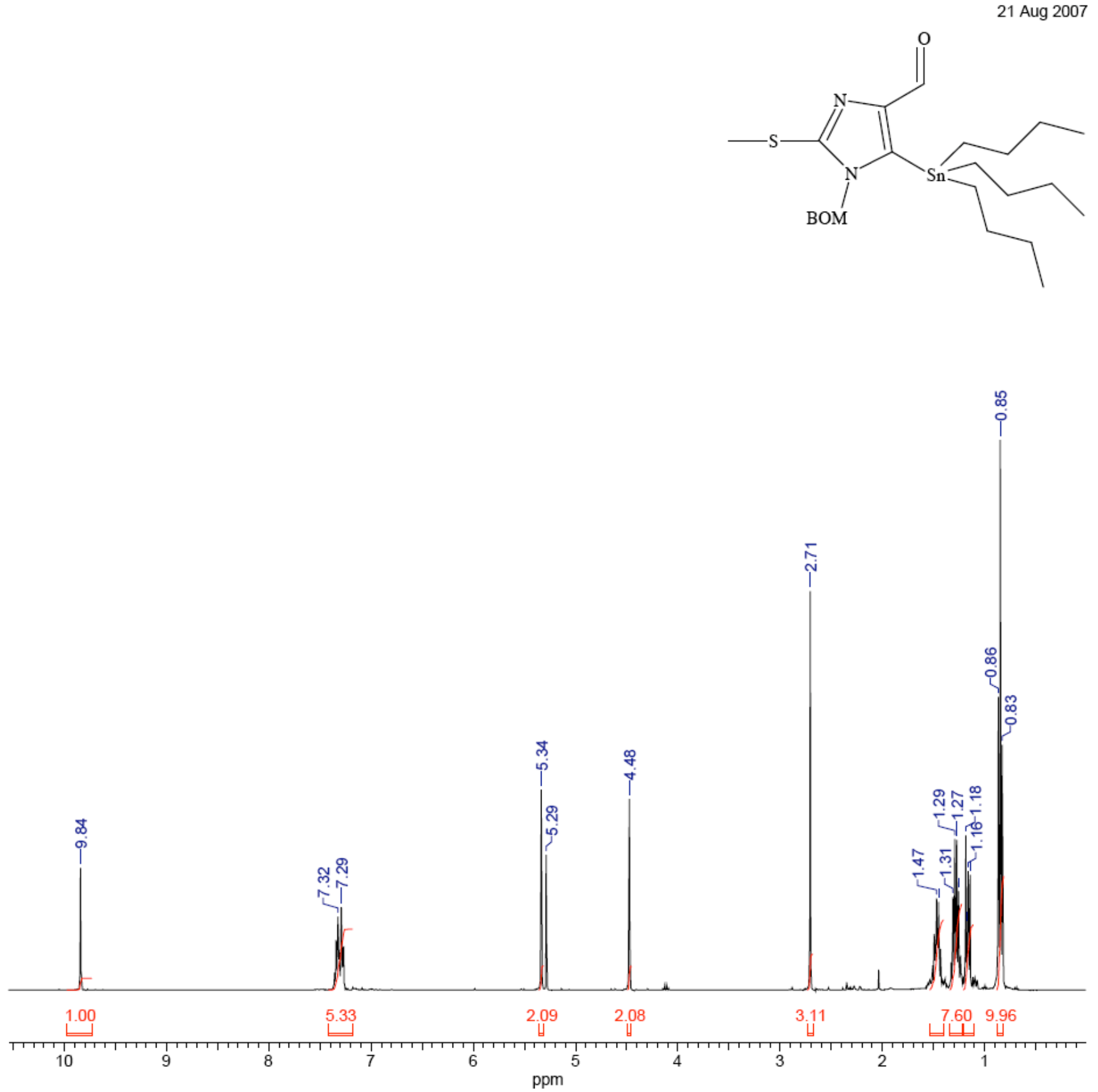

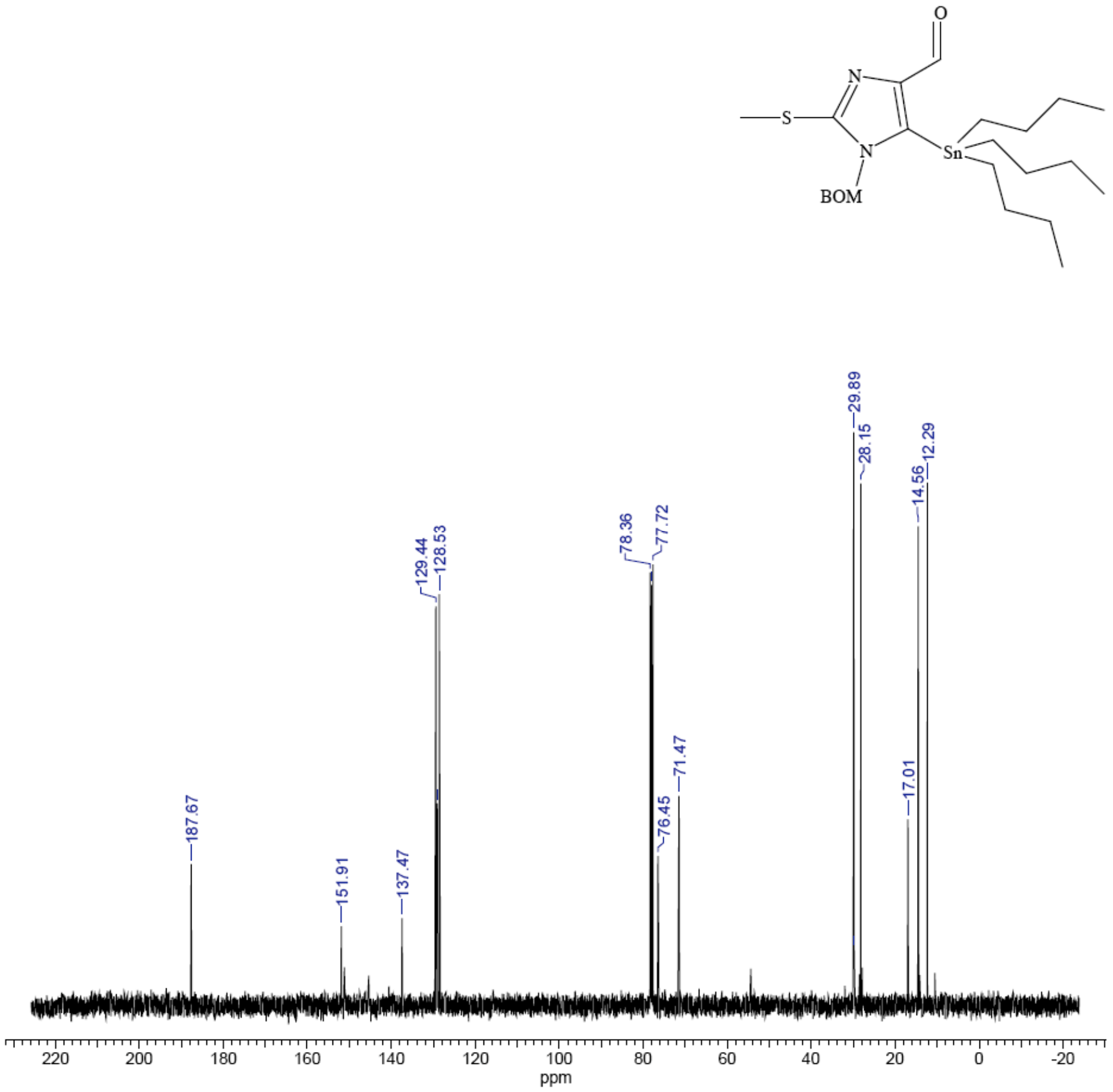
21 Aug 2007

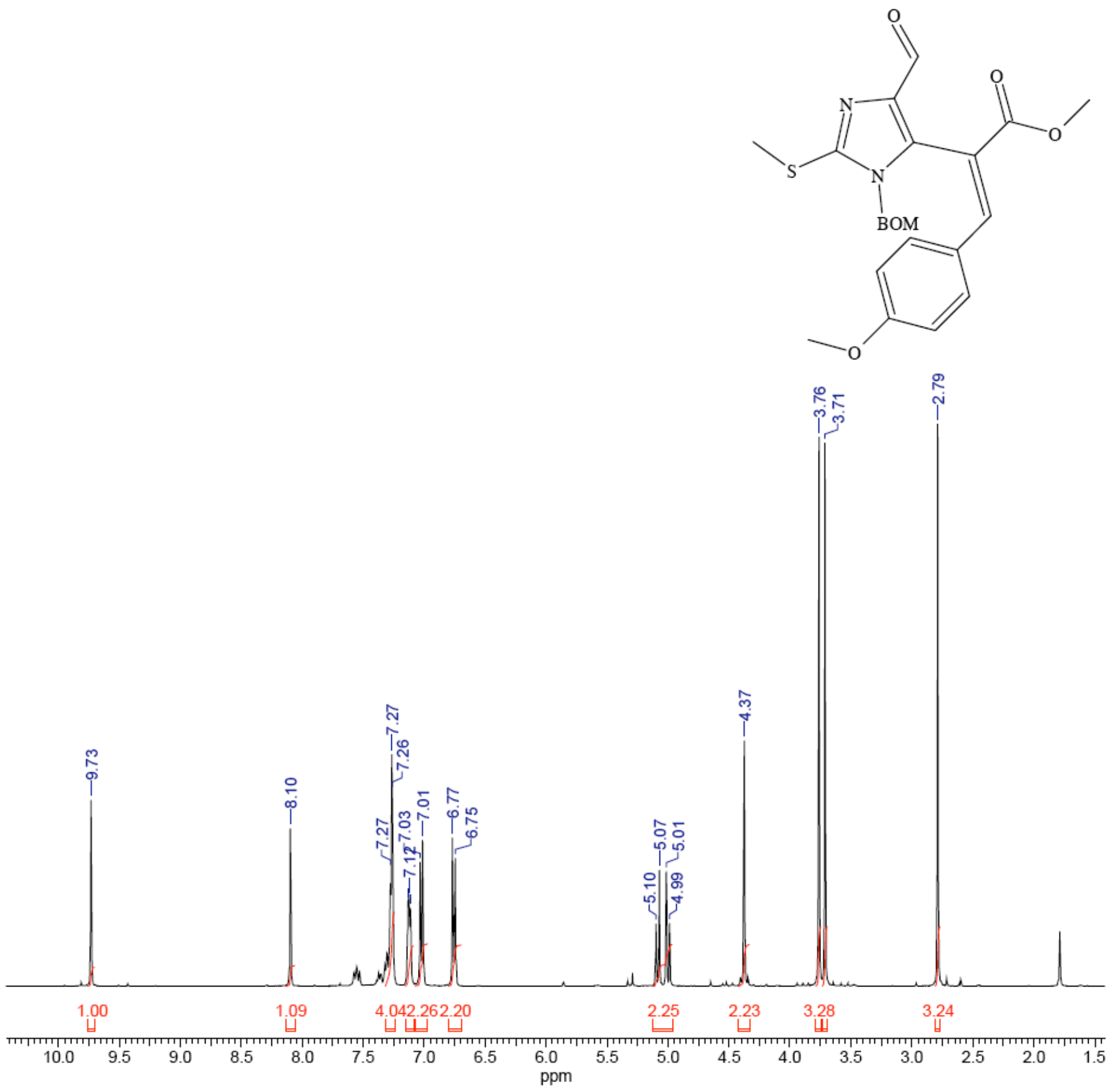


21 Aug 200/

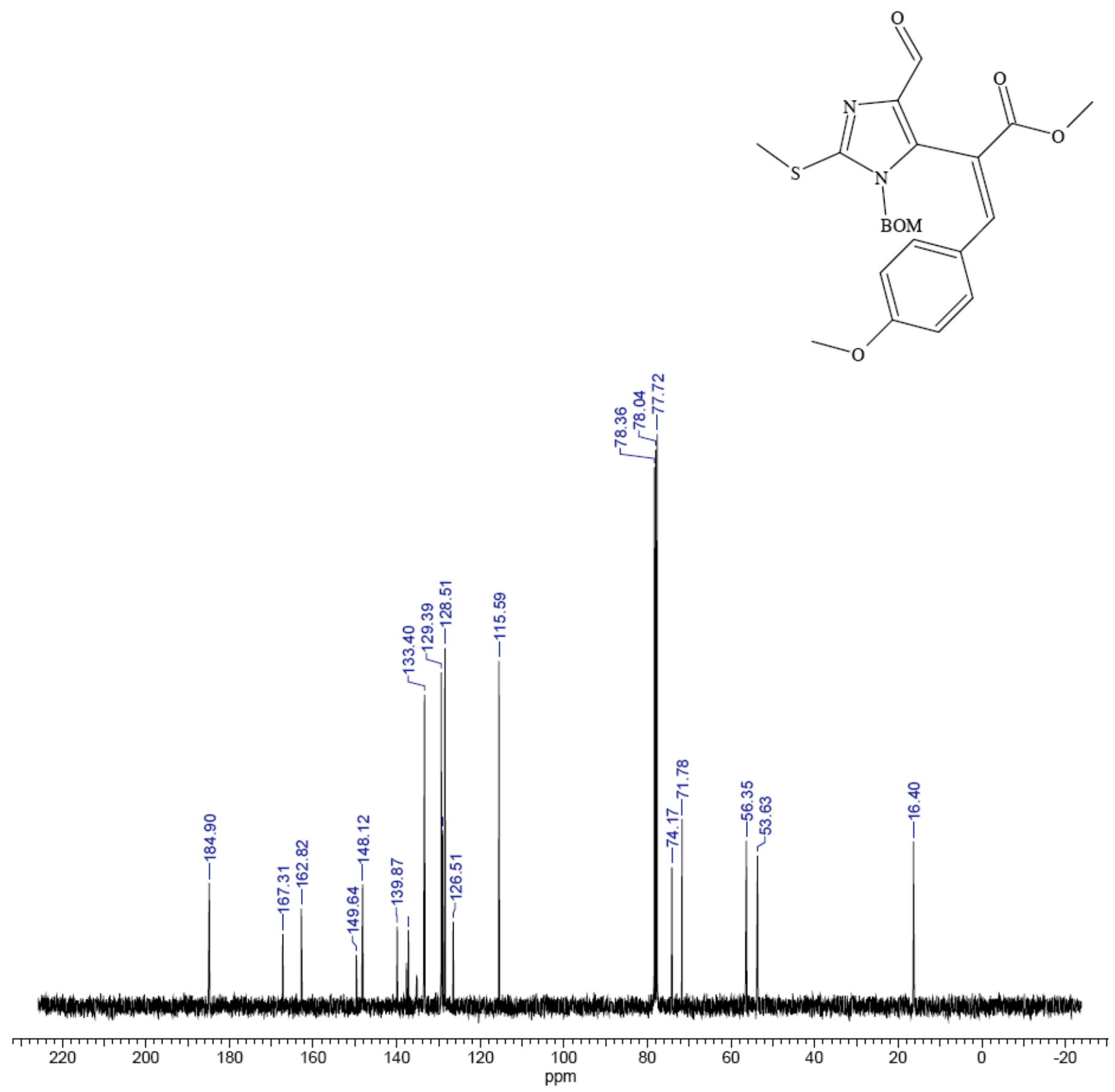


21 Aug 2007

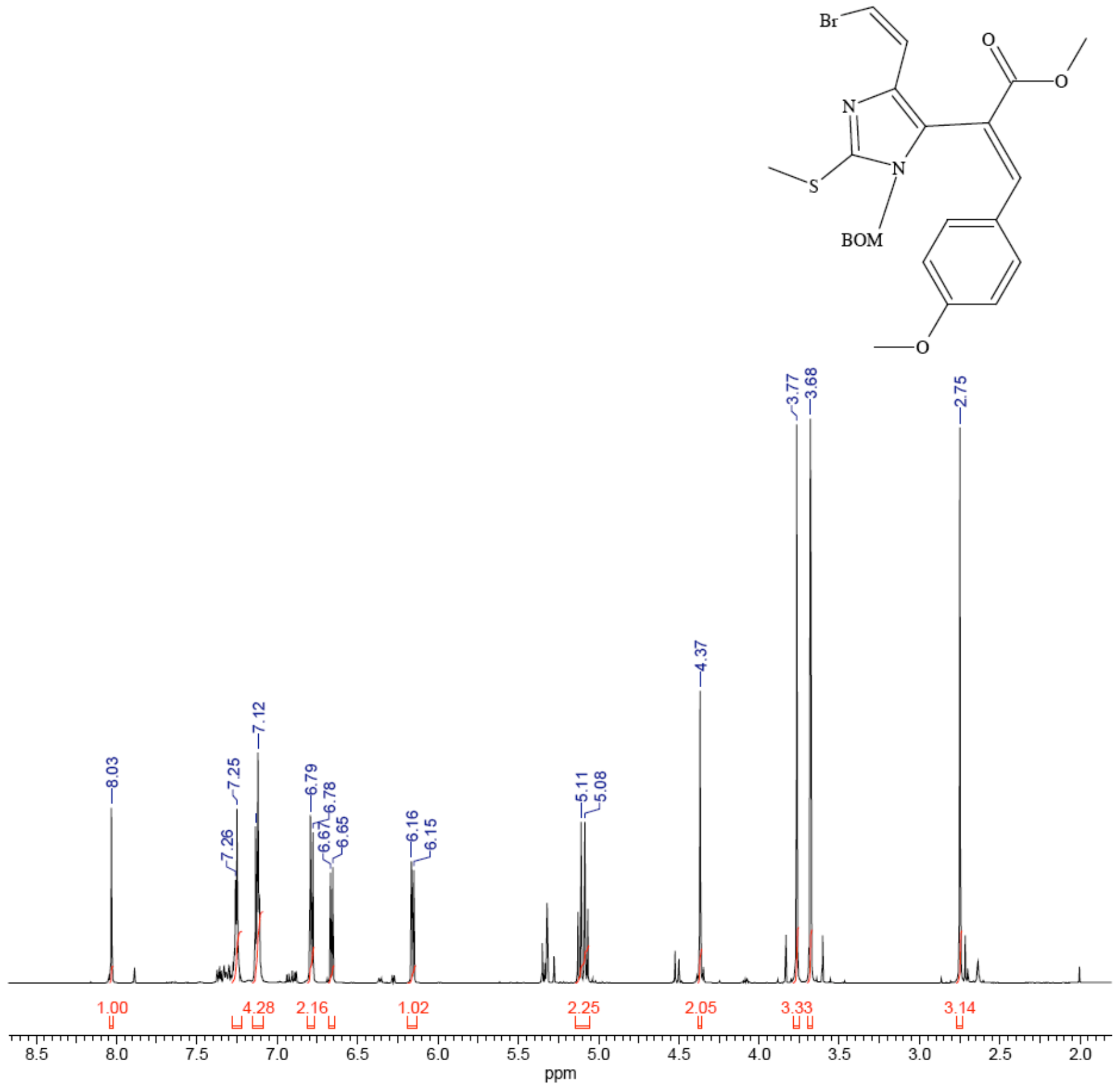



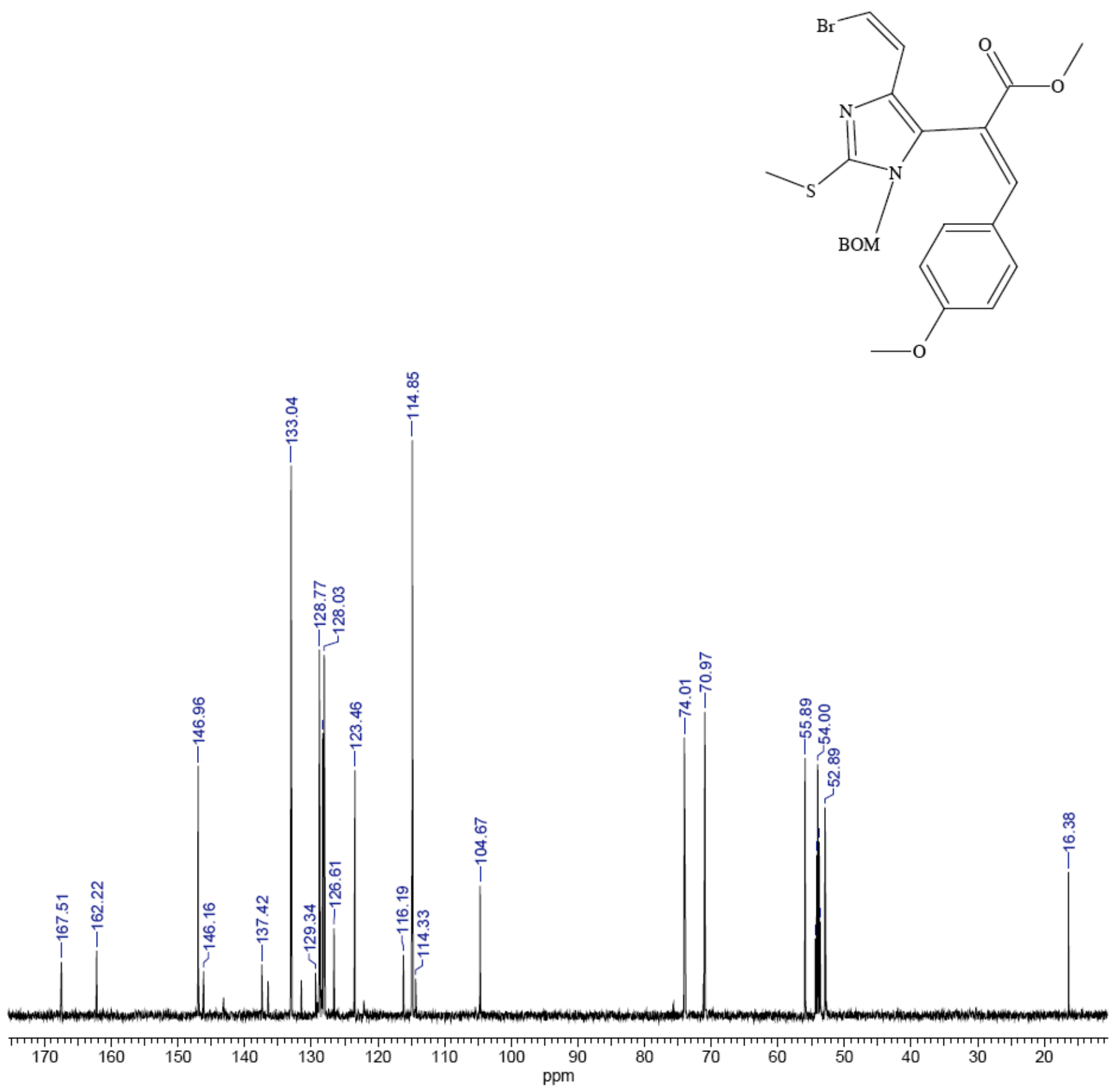

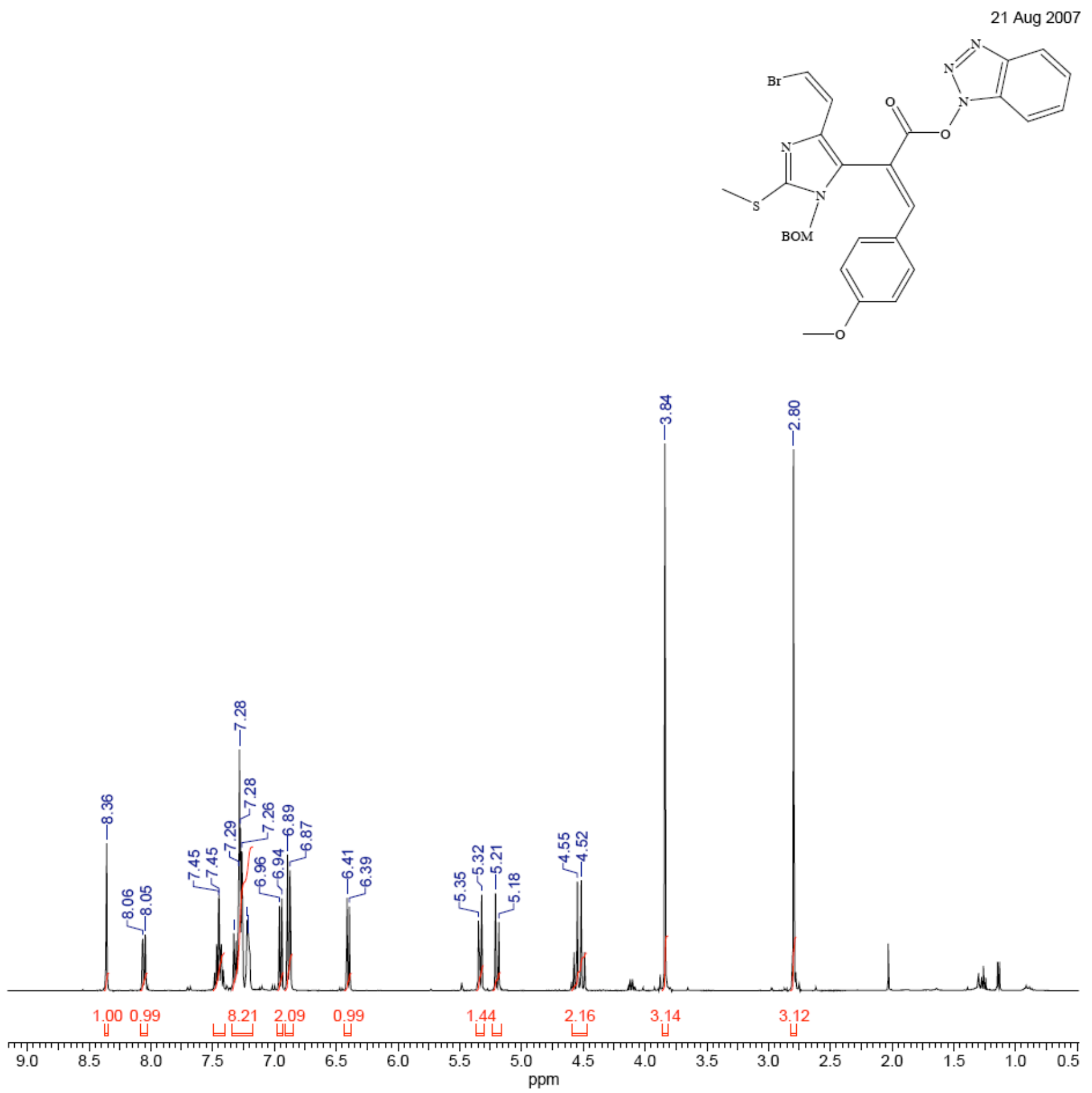


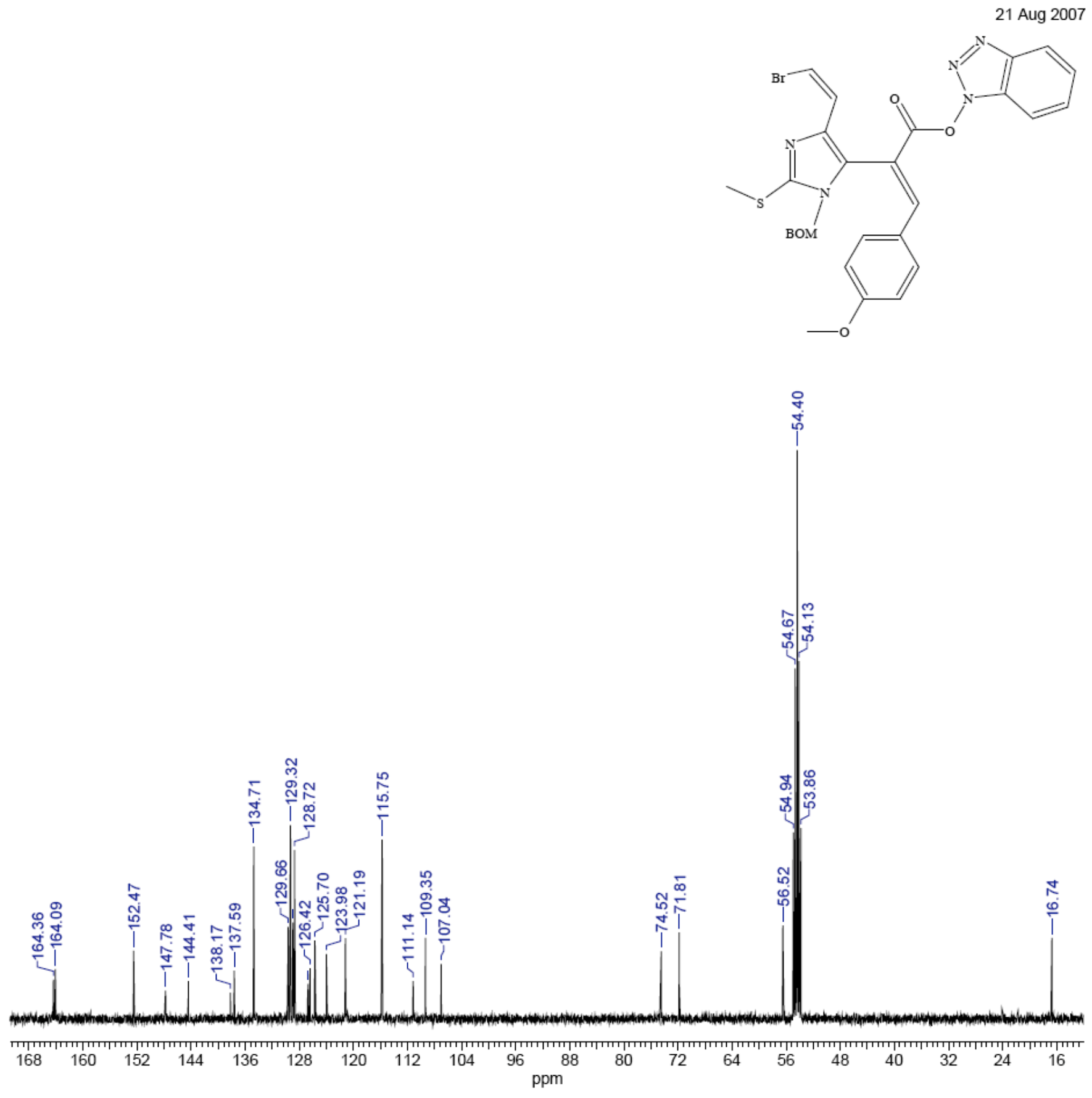


21 Aug 2007
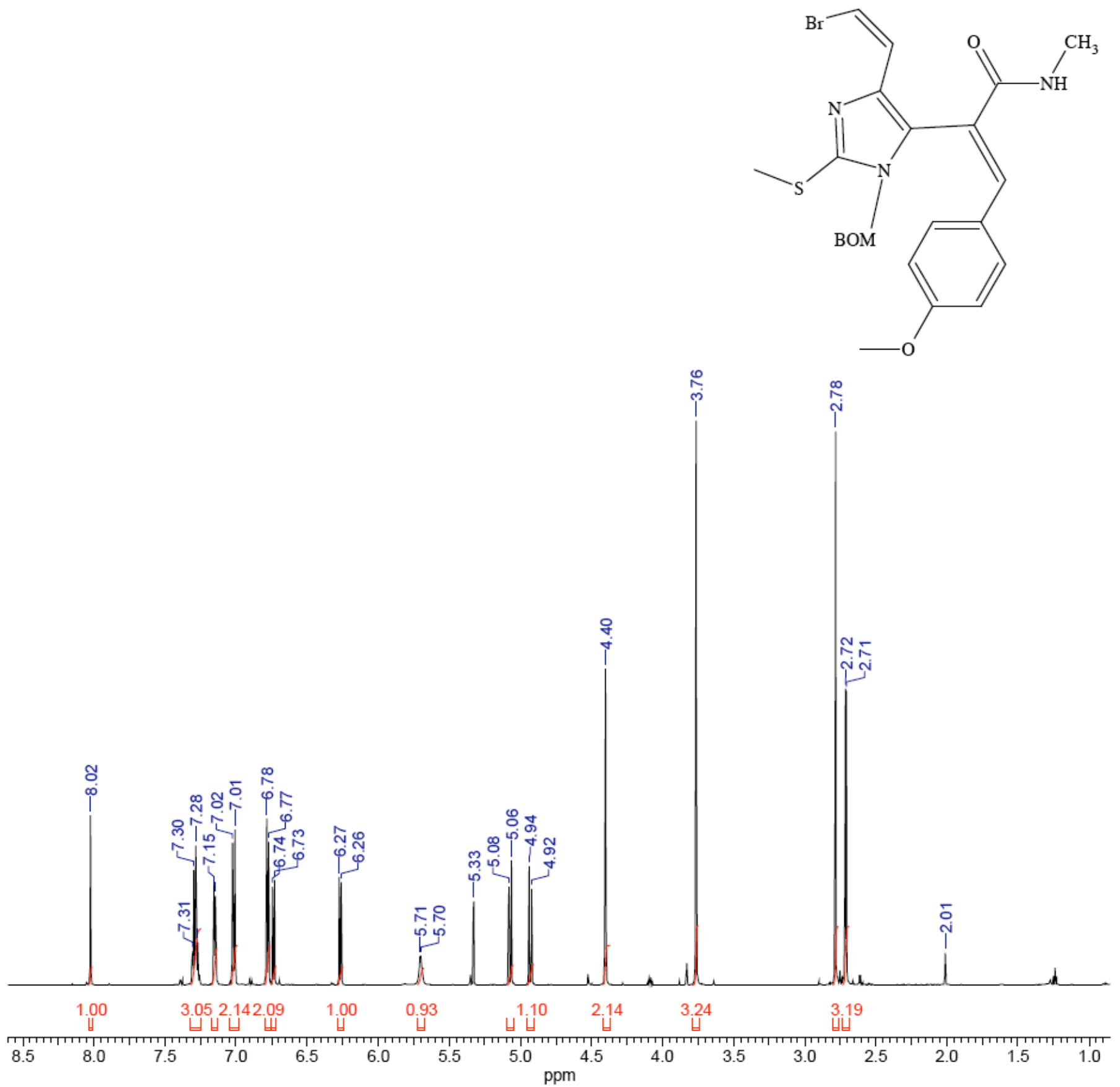


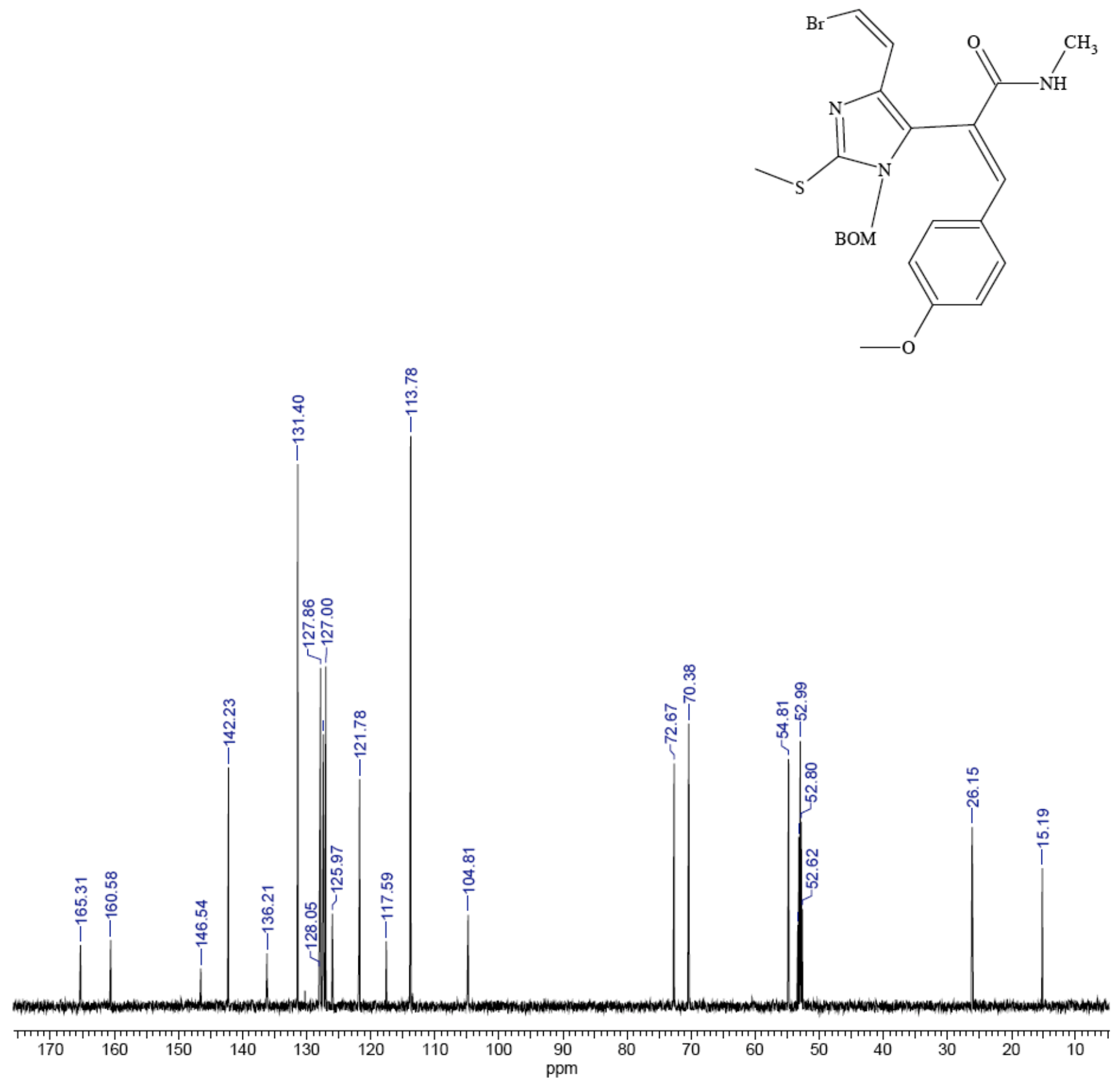




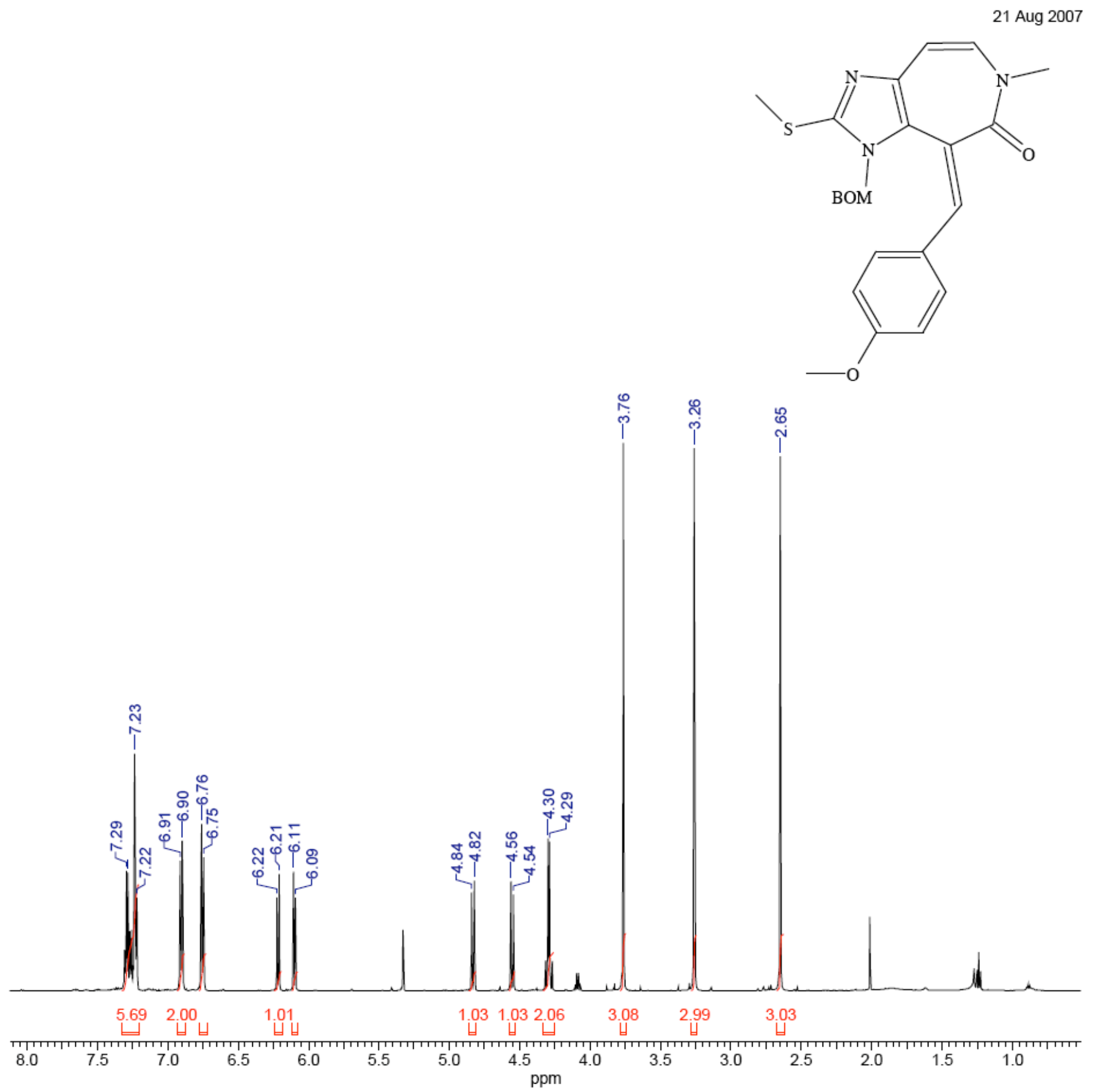



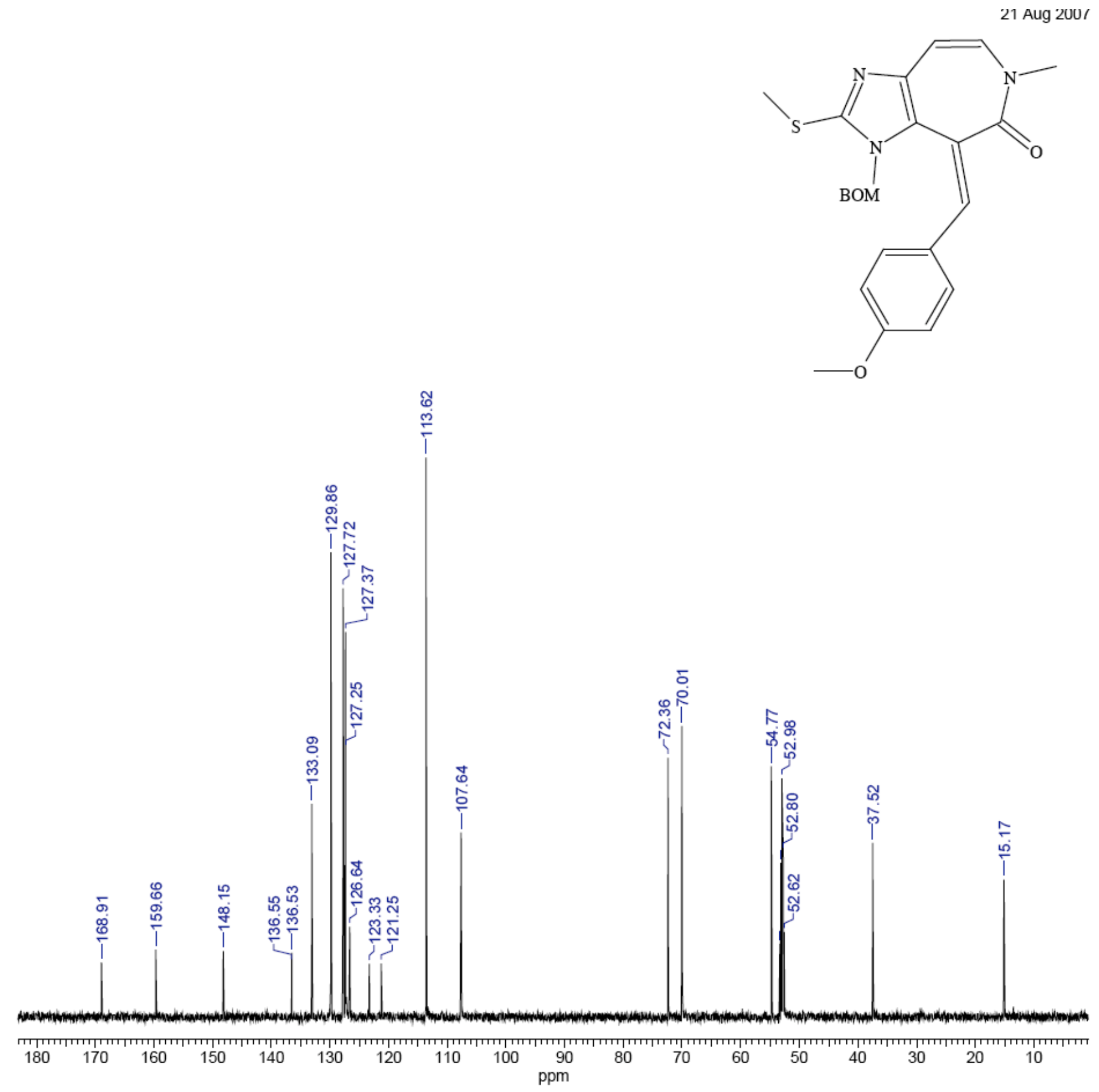
21 Aug 2007
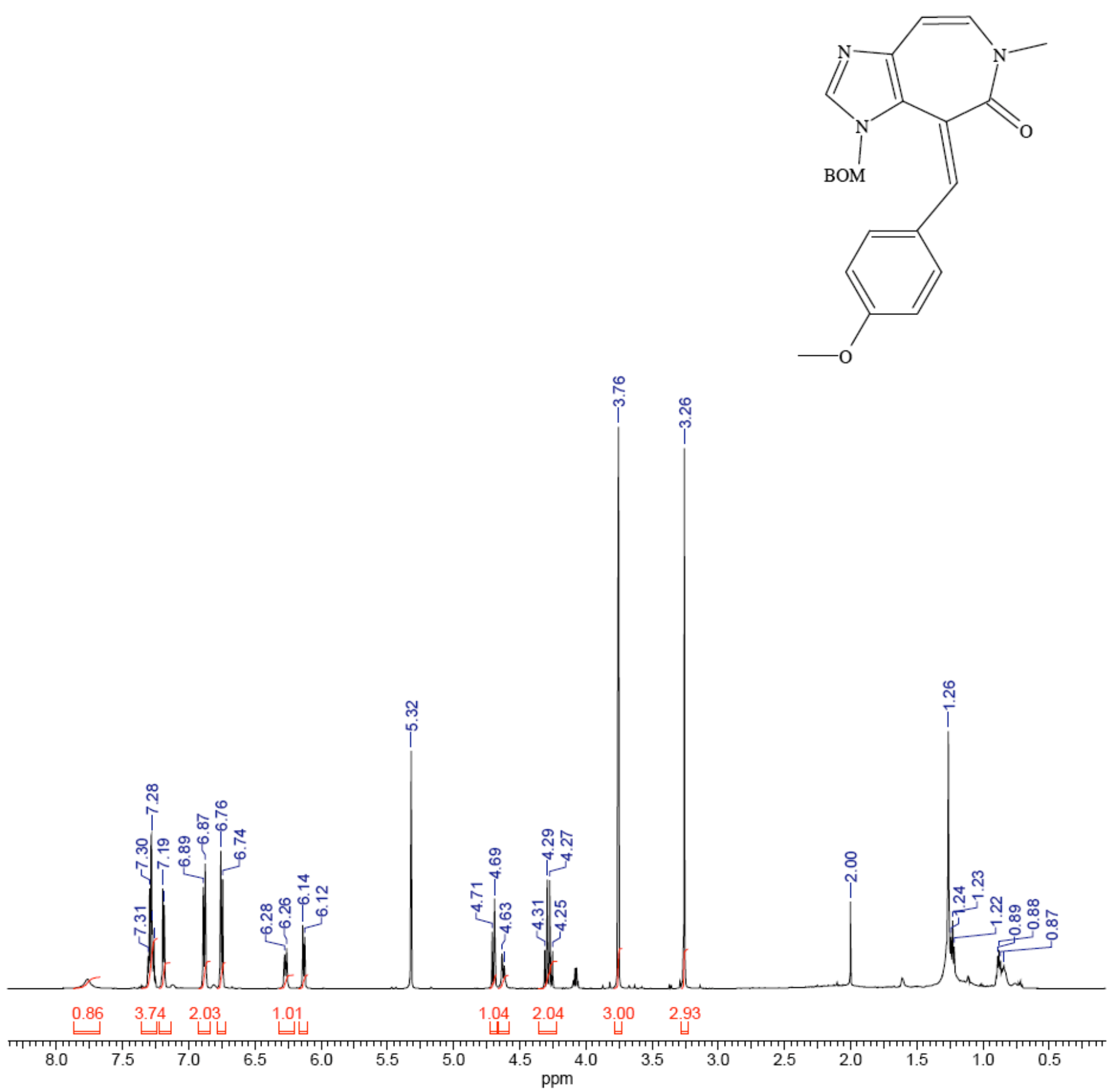


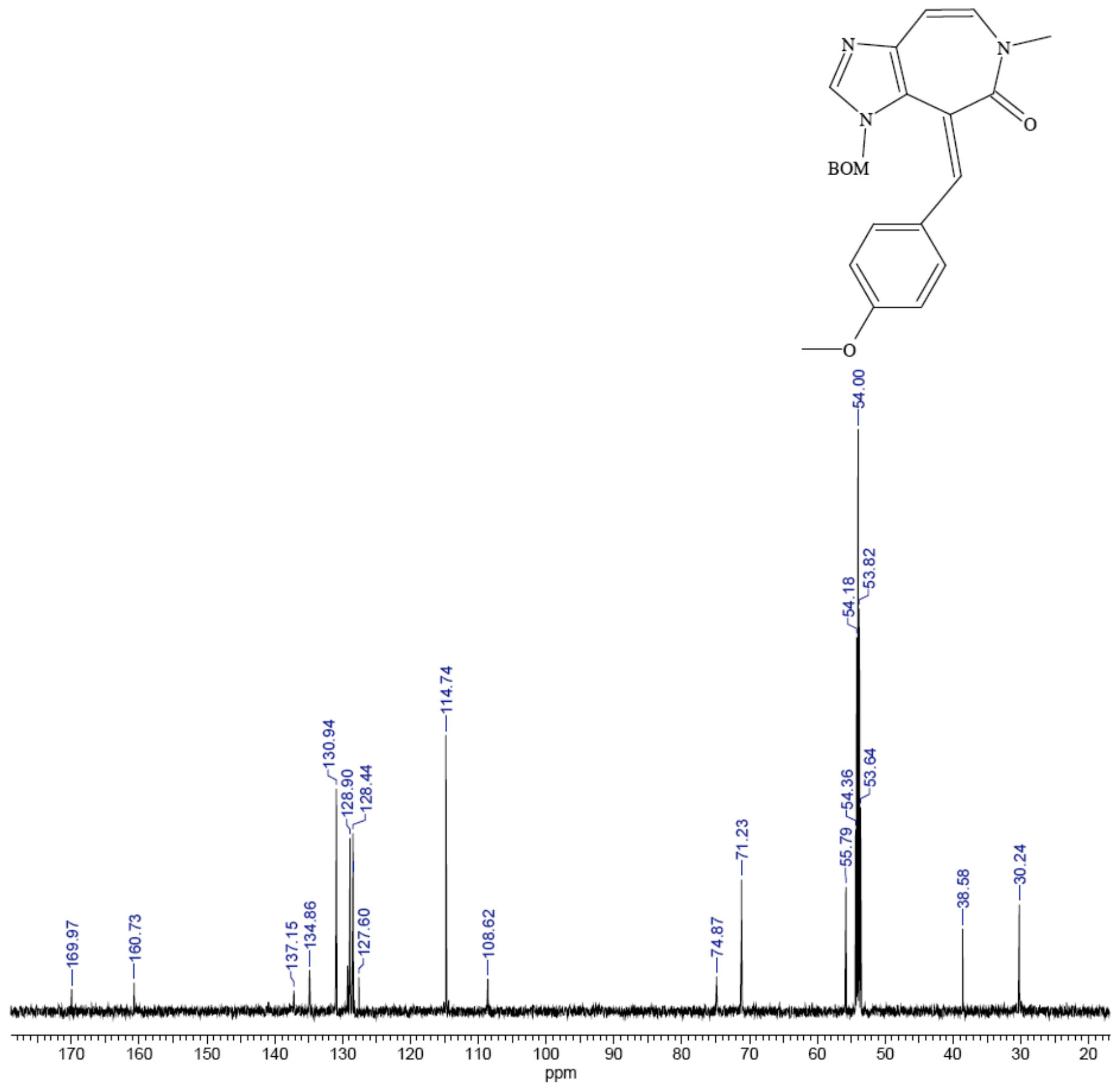




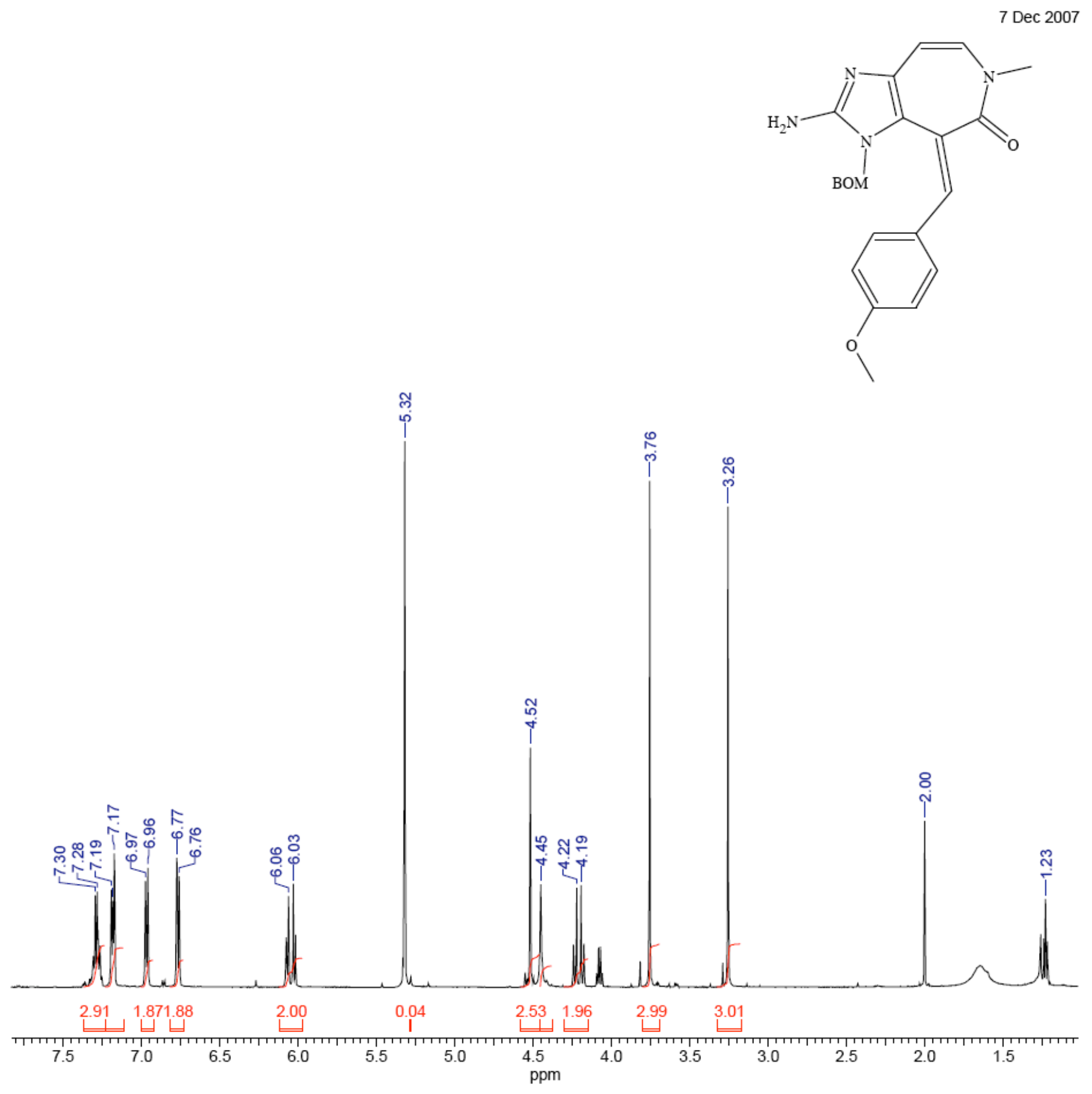


SI21

7 Dec 2007

띠윯

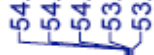<smiles>C=C1C(=O)N(C)C=Cc2nc(N)n(C(C)(C)C)c21</smiles>
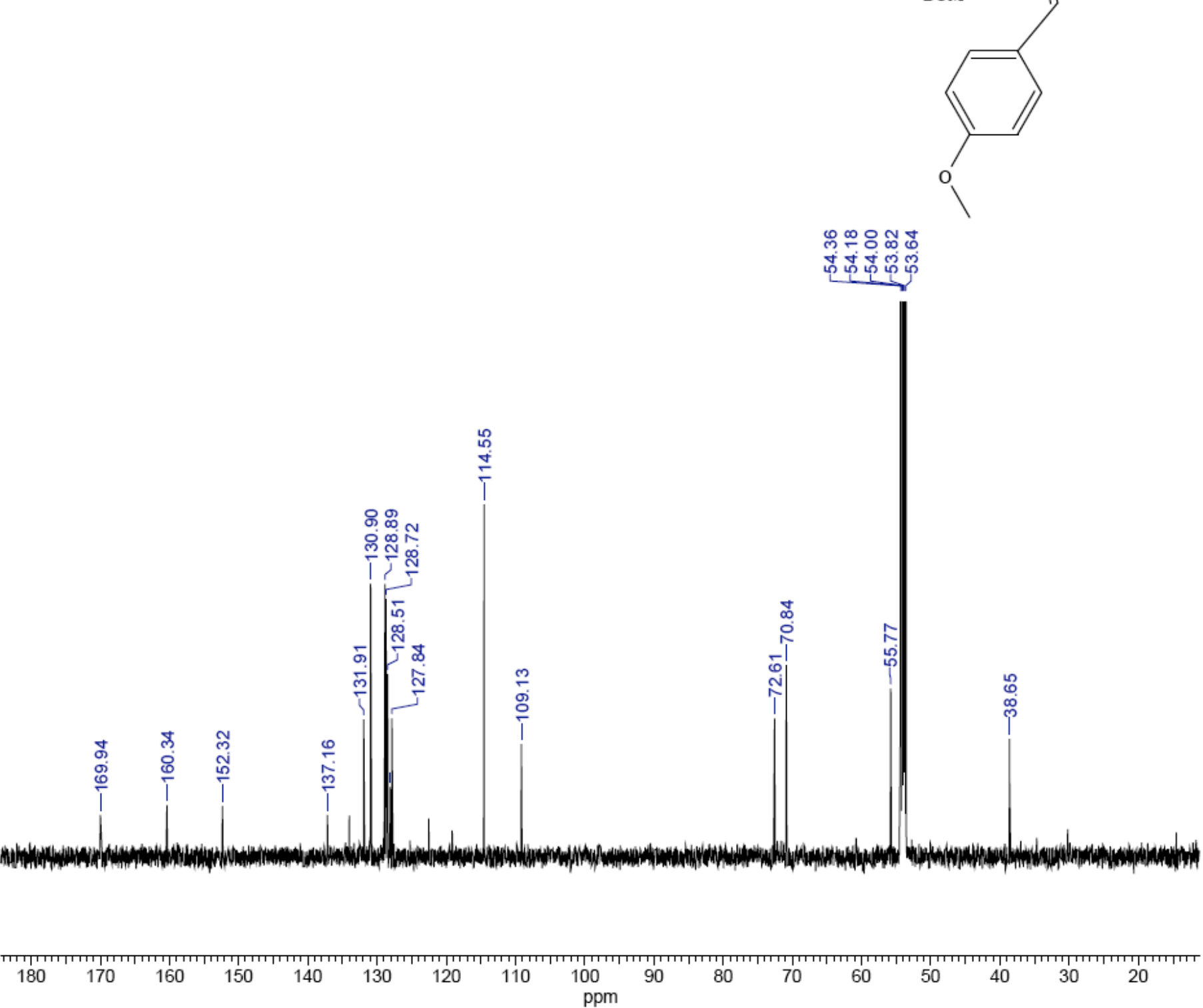
7 Dec 2007
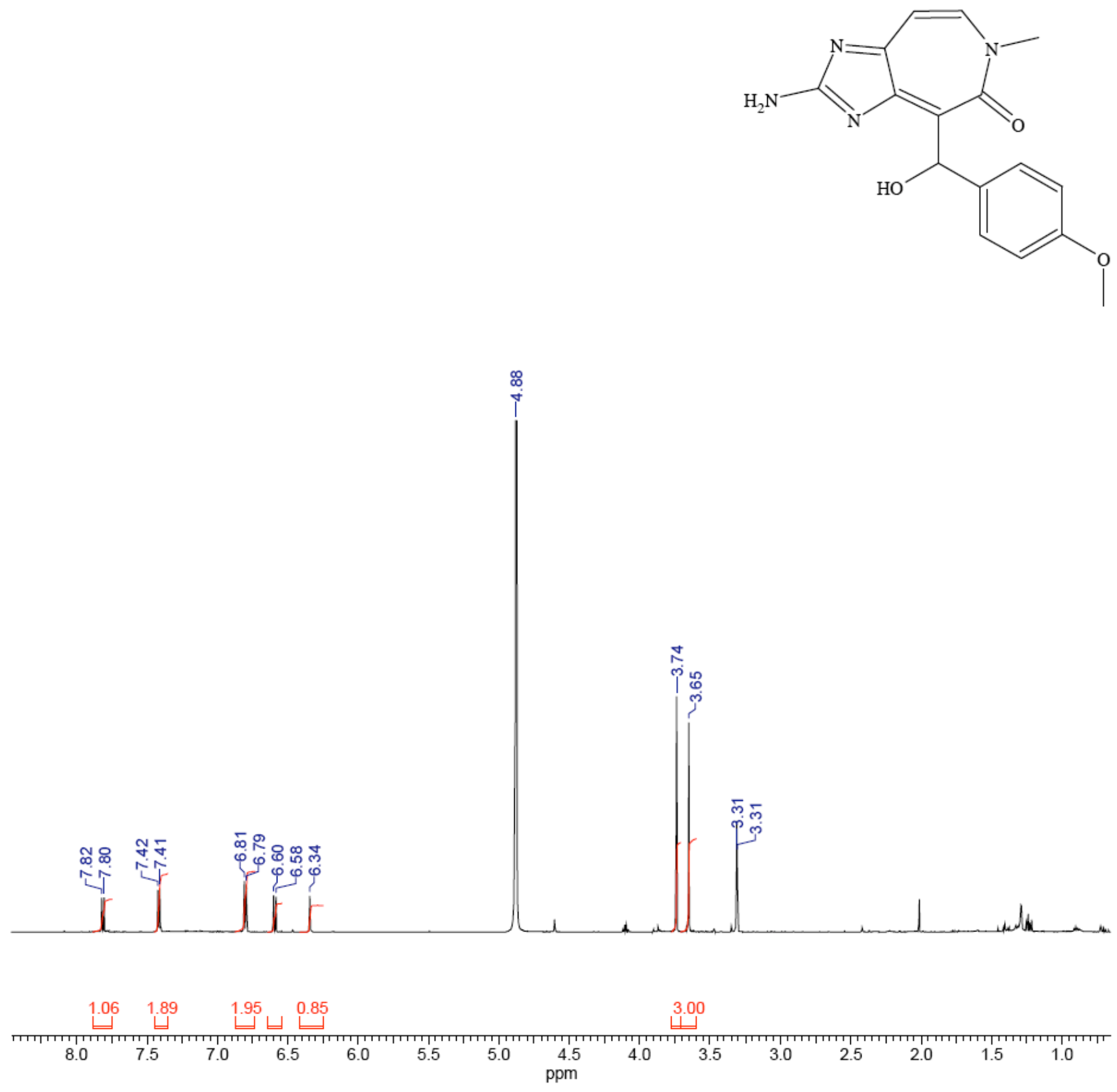
7 Dec 2007

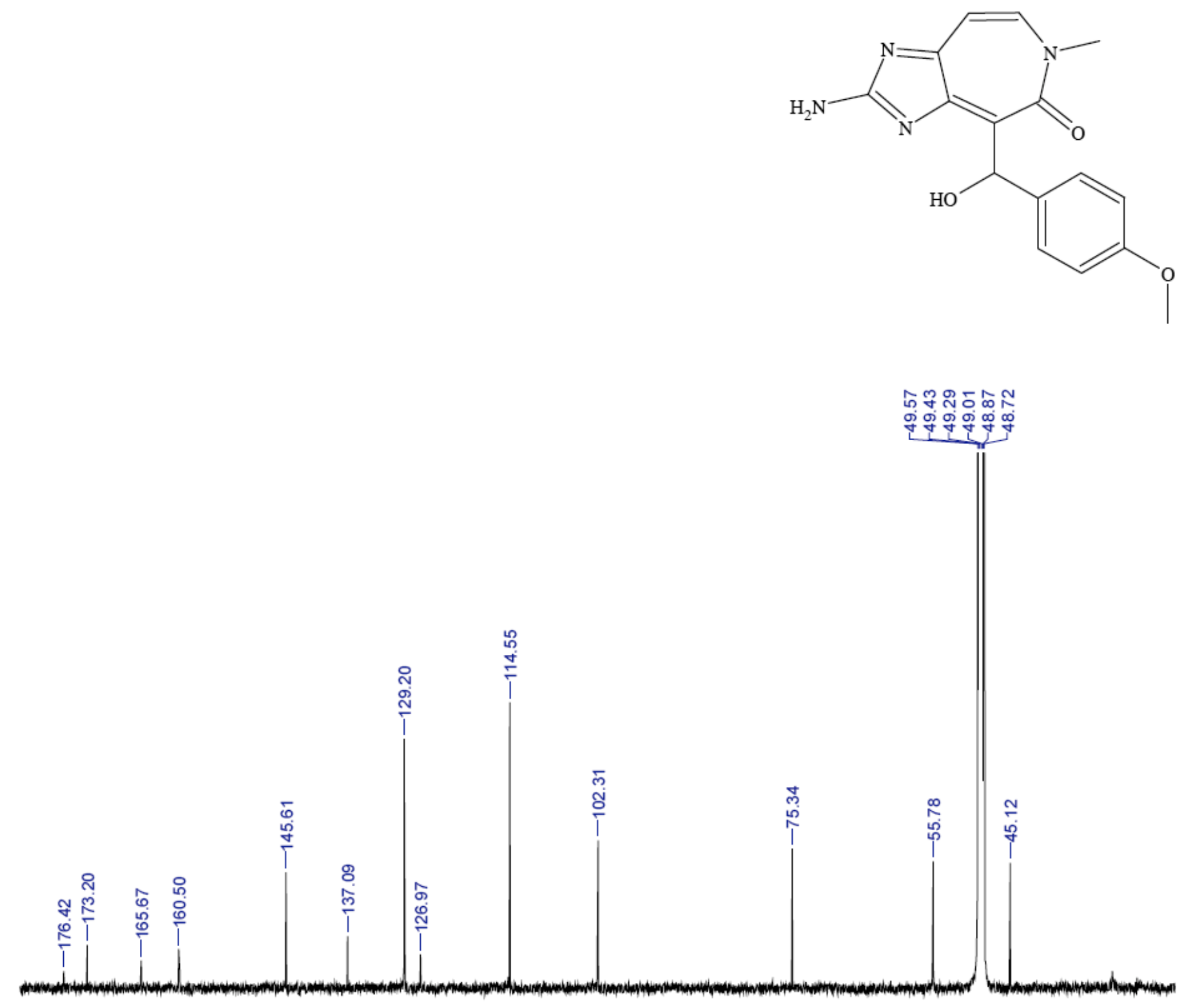

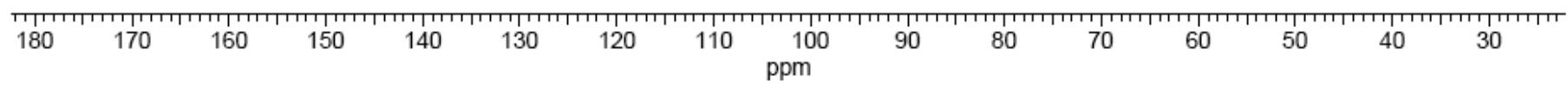




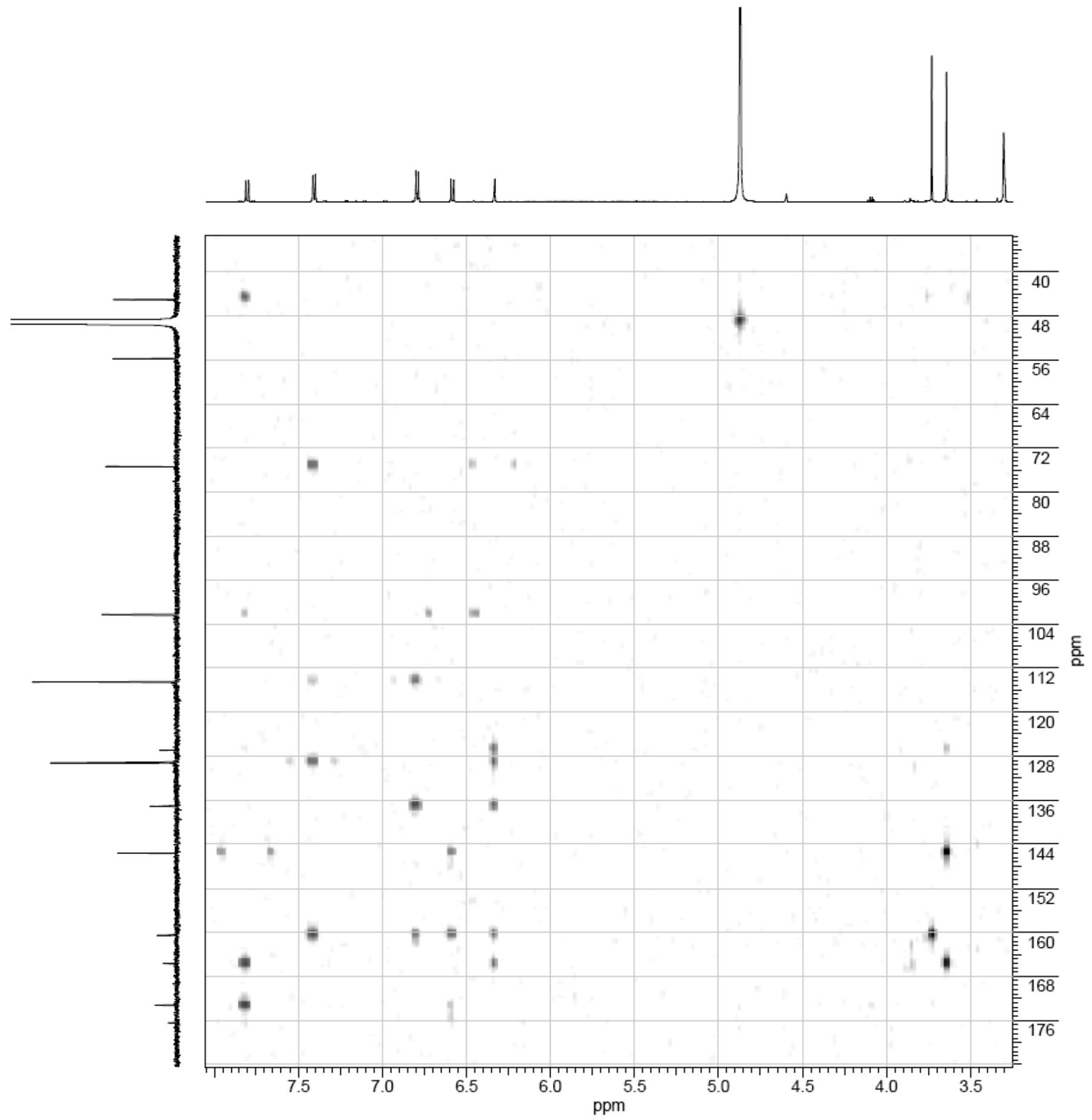




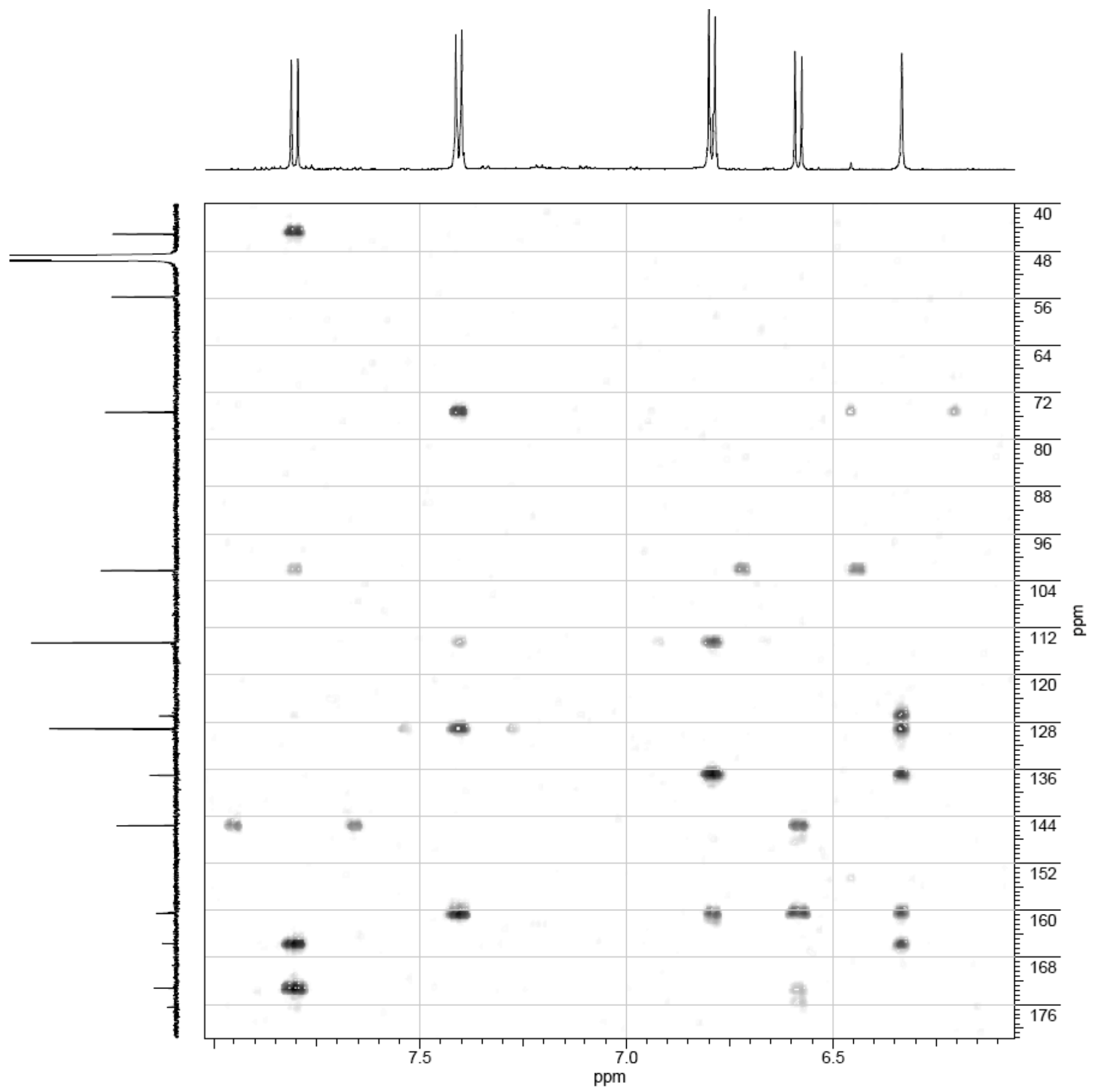


10 Dec 2007
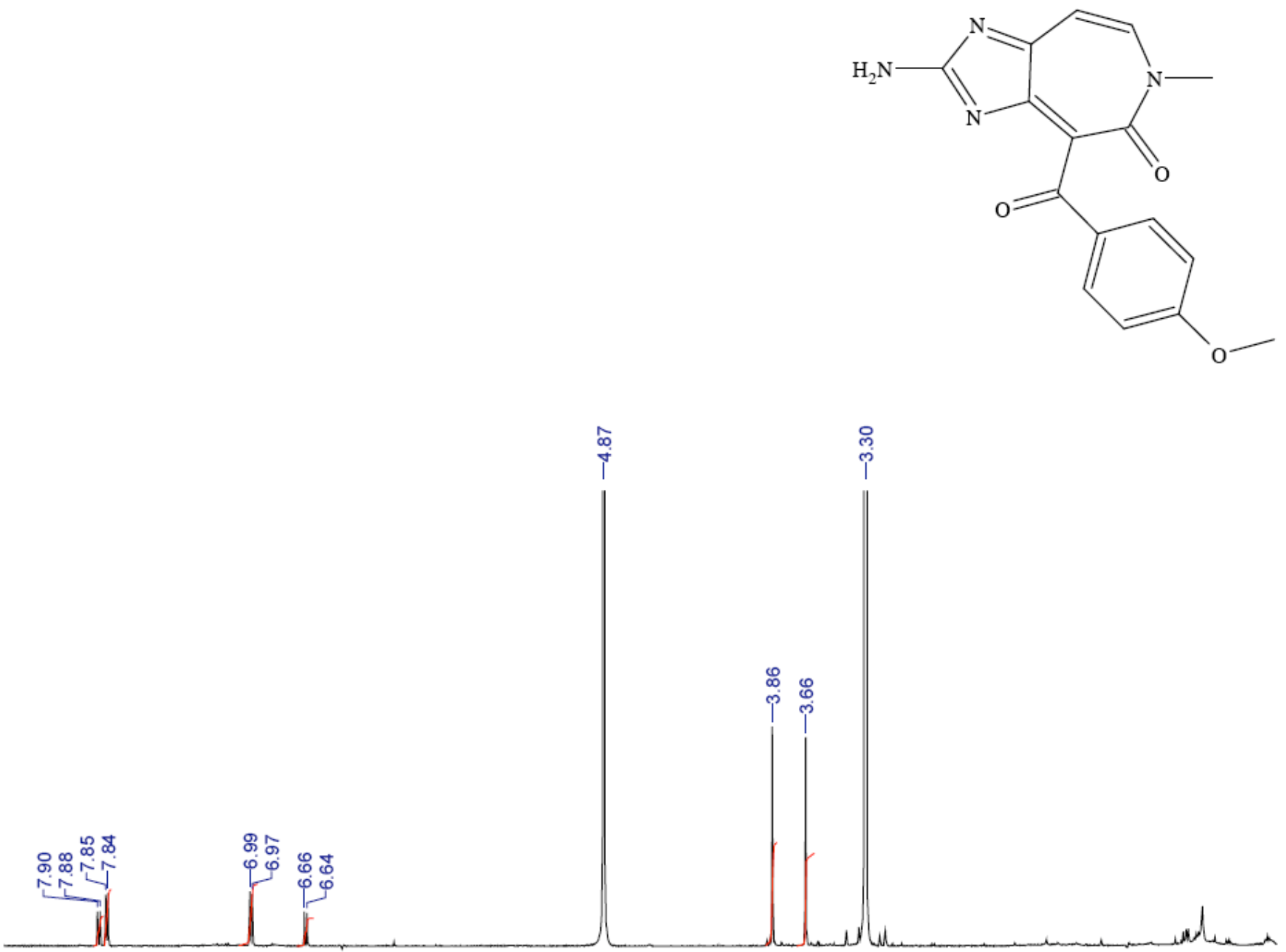


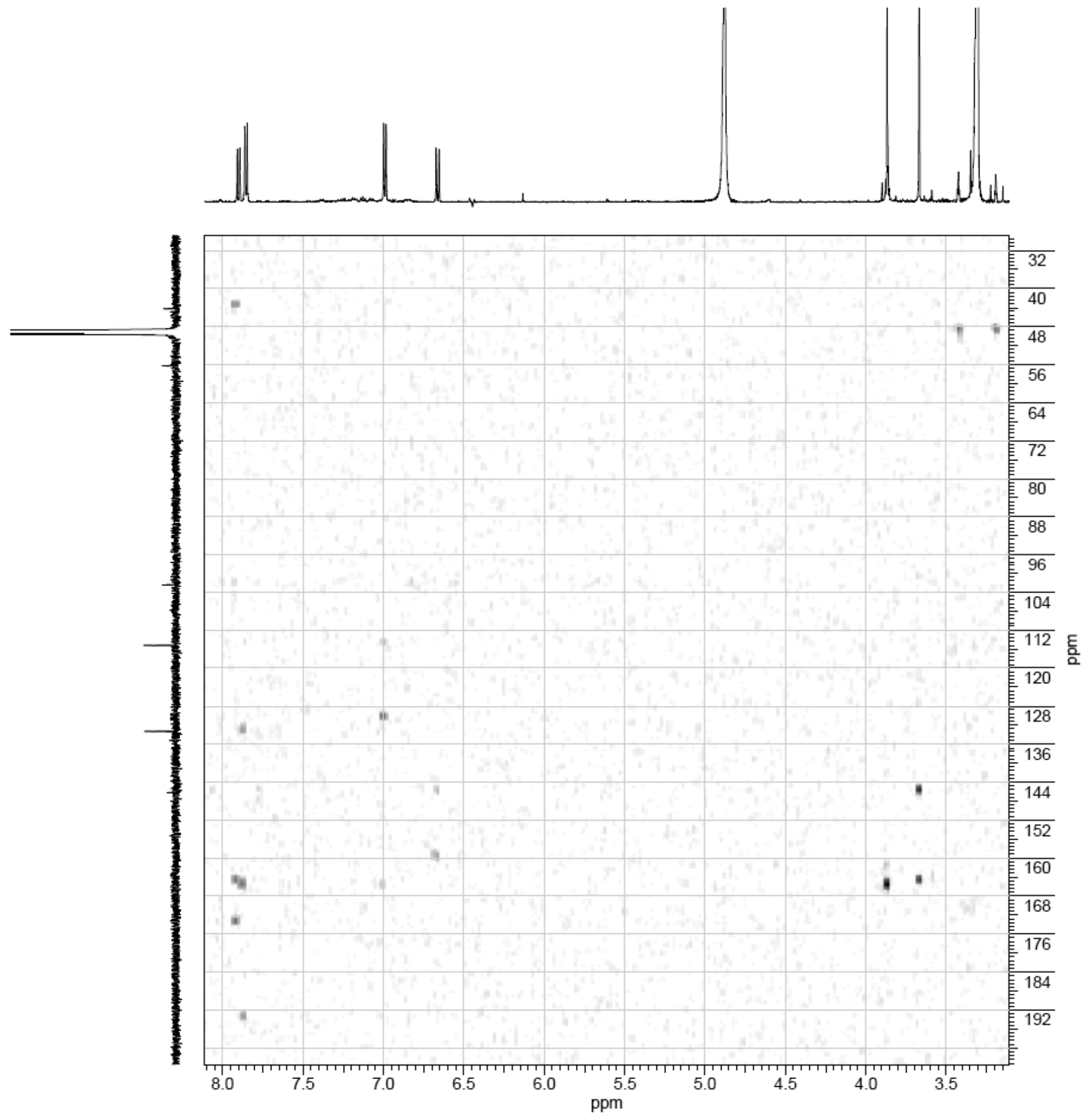


SI28

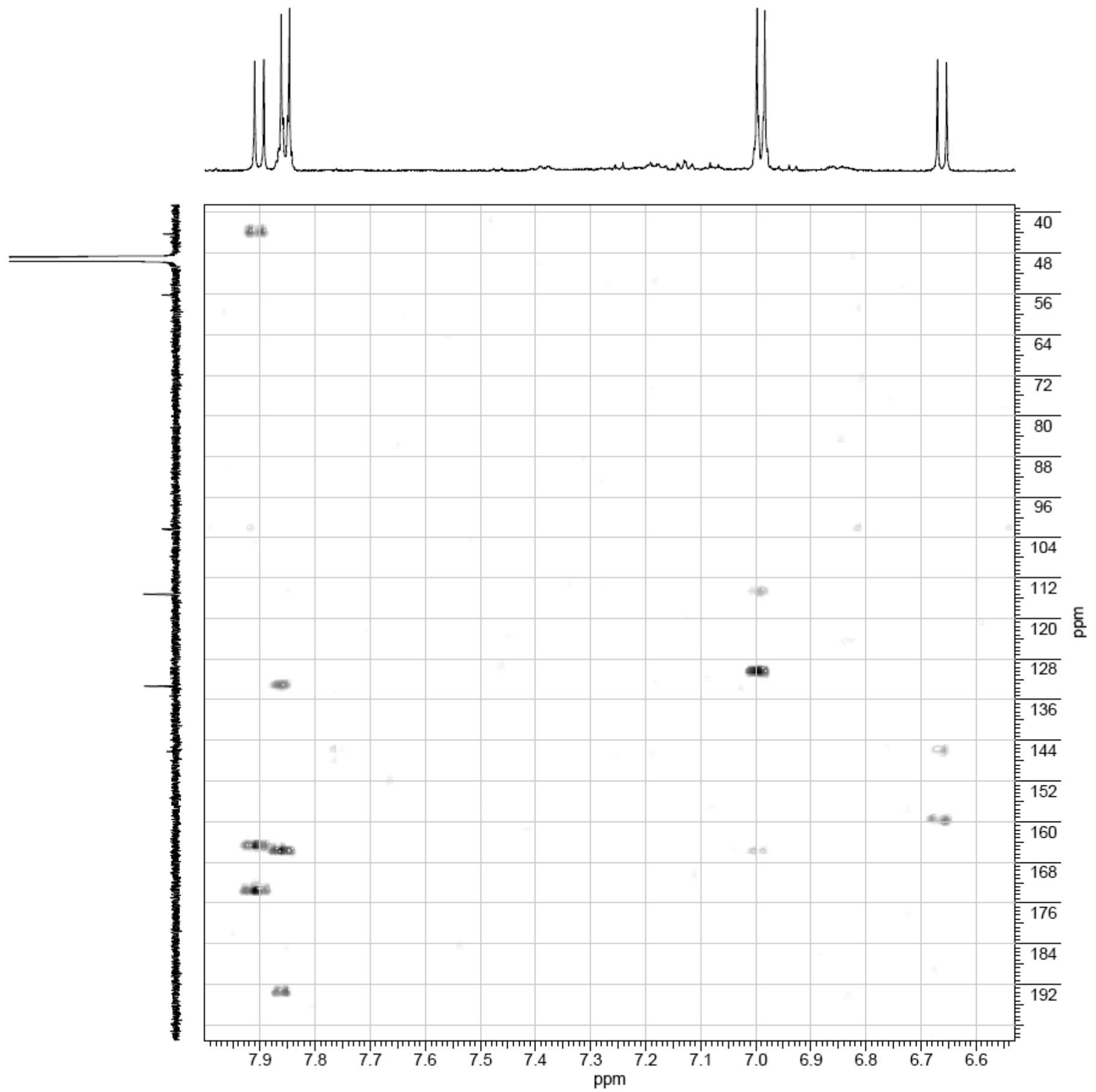


7 Dec 2007
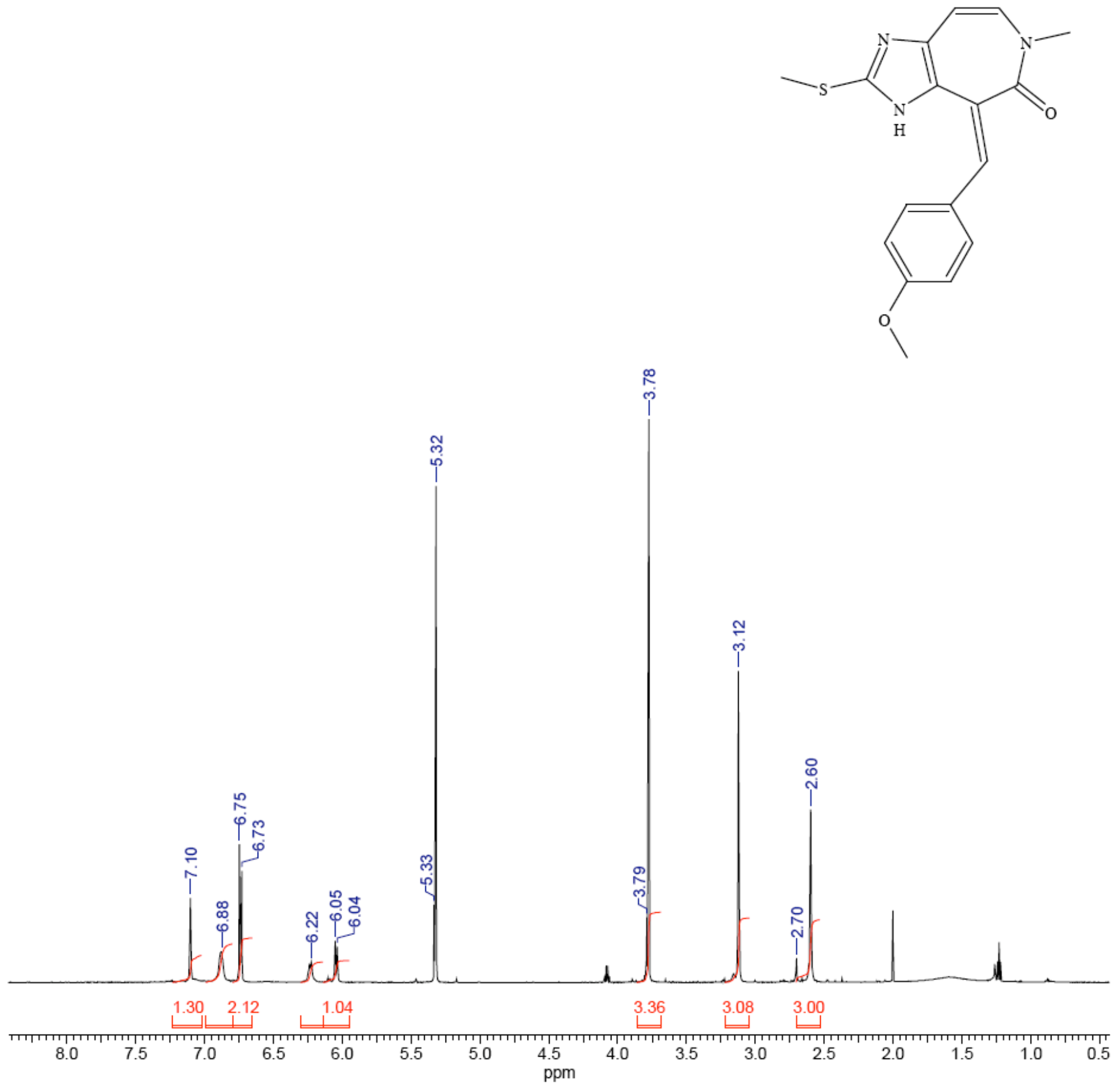
7 Dec 2007

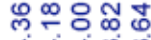
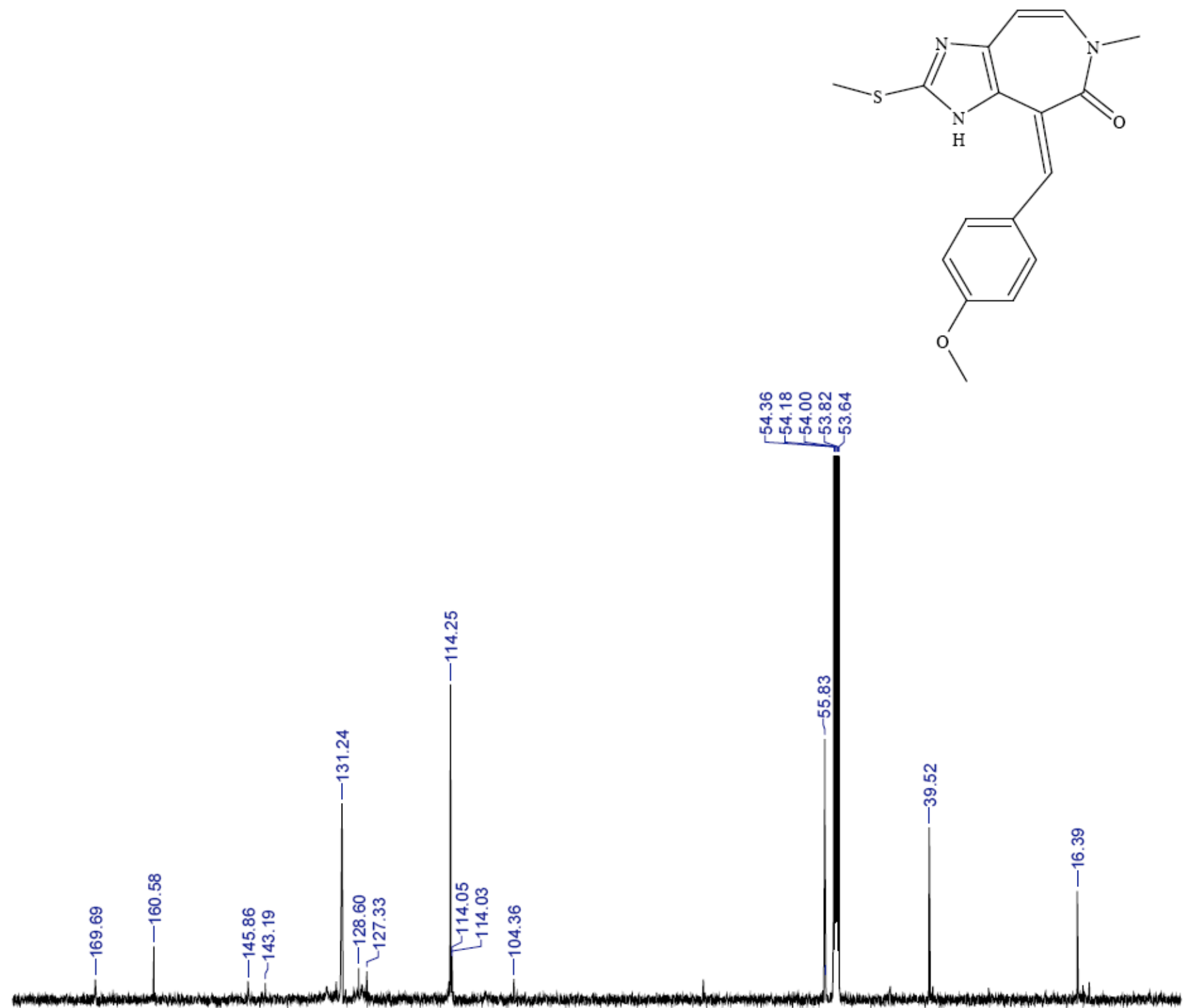

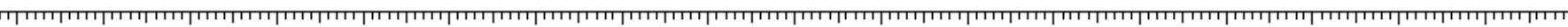

$140 \quad 130$

$120 \quad 11$

100

90

70 
SI31

21 Aug 2007
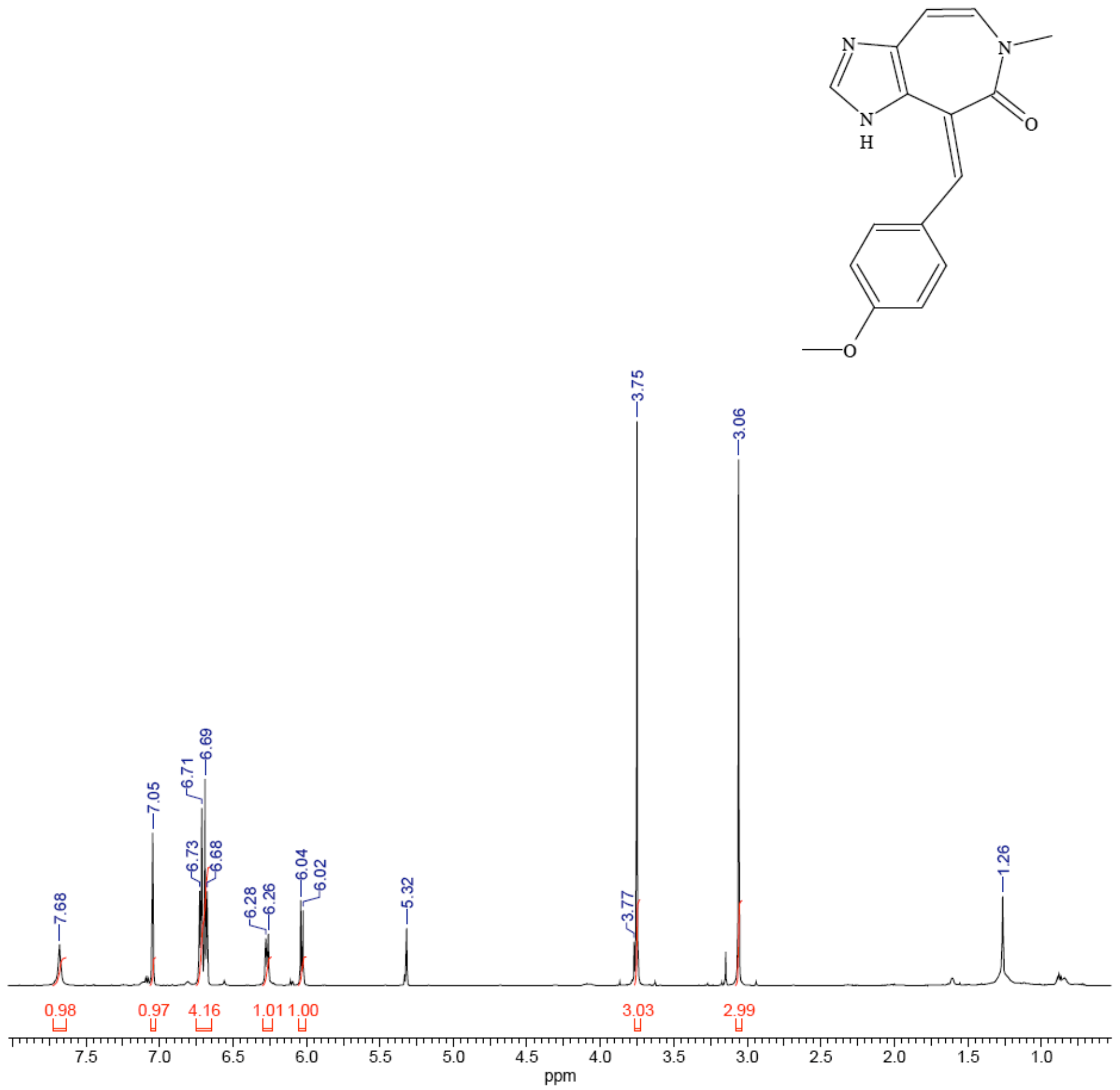
SI32

21 Aug 2007

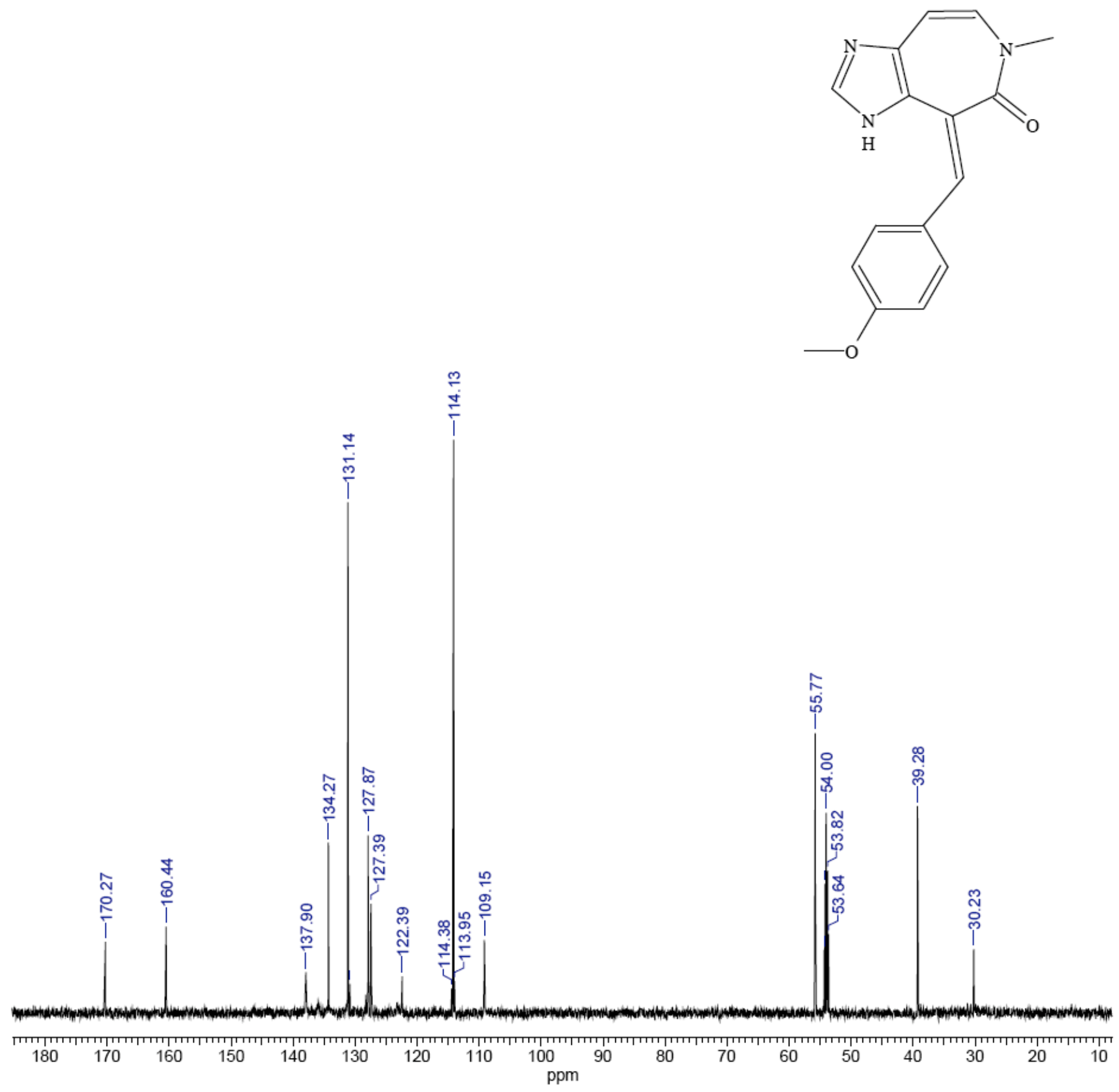




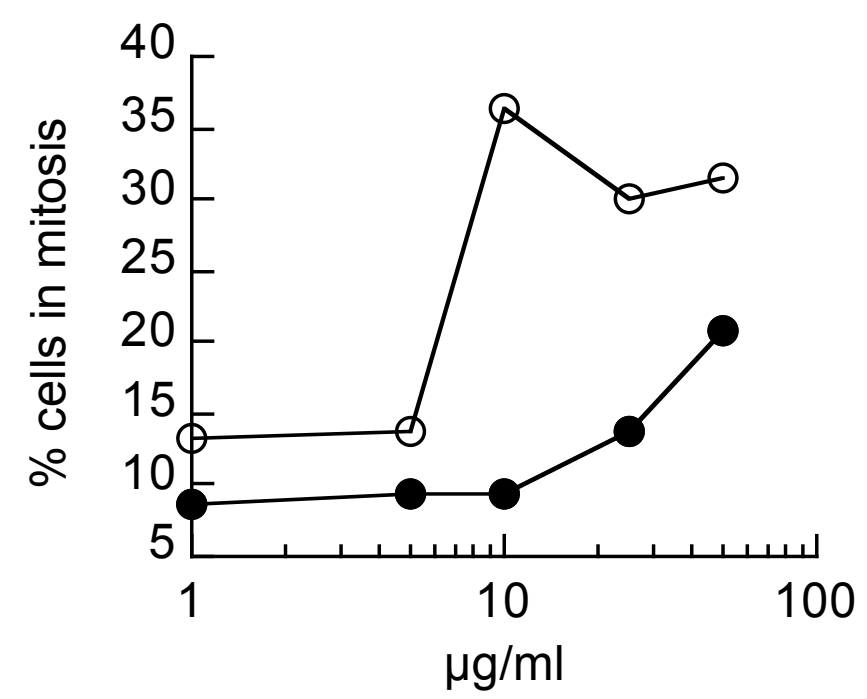

Supplementary Figure 1. Antimitotic activity of 21. MDA-MB-231 human breast cancer cells were exposed to different concentrations of $21(O)$ or ceratamine A $(O)$ for $16 \mathrm{~h}$ and the percentage of cells arrested in mitosis was determined using mitotic spreads (Roberge, M., Tudan, C., Hung, S. M. F., Harder, K. W., Jirik, F. R. and Anderson, H. J. Cancer Res. 54:6115-6121, 1994). Compound 22 showed activity comparable to 21. The small amounts of 22 available were not adequate to generate a dose response curve. 